\title{
Non-halogenated Imidazolium and Phosphonium-based Surface-Active Ionic Liquids as Electrolytes for Supercapacitors
}

\author{
Preeti Jain $^{a *}$, Oleg N. Antzutkin ${ }^{\text {ab }}$ \\ ${ }^{\mathrm{a}}$ Chemistry of Interfaces, Luleå University of Technology, SE-97 187, Luleå, Sweden \\ ${ }^{\mathrm{b}}$ Department of Physics, Warwick University, CV4 7AL, Covertly, United Kingdom
}

*E-mails: preeti.9jain@gmail.se; Oleg.Antzutkin@1tu.se

\begin{abstract}
We report a comparative analysis of three novel non-halogenated surface-active ionic liquids (SAILs), which consist of a surface-active anion, 2-ethylhexyl sulfate ([EHS] $]^{-}$), and phosphonium or imidazolium cations: tetrabutylphosphonium $\left(\left[\mathrm{P}_{4,4,4,4}\right]^{+}\right)$, trihexyl(tetradecyl)phosphonium $\left(\left[\mathrm{P}_{6,6,6,14}\right]^{+}\right)$, and 1-methyl-3-hexylimidazolium $\left(\left[\mathrm{C}_{6} \mathrm{C}_{1} \mathrm{Im}\right]^{+}\right)$. We explored thermal properties (degradation, melting and crystallisation temperatures) of these novel SAILs and their electrochemical properties (ionic conductivity and electrochemical potential window, ECW). These SAILs were tested as electrolytes in a multi-walled carbon nanotubes (MWCNTs)-based supercapacitor at various temperatures from 253 to $373 \mathrm{~K}$ and their electrochemical performance as a function of temperature was compared. We found that the supercapacitor cell with $\left[\mathrm{C}_{6} \mathrm{C}_{1} \mathrm{Im}\right][\mathrm{EHS}]$ as an electrolyte has shown a higher specific capacitance $\left(C_{\text {elec }}\right.$ in $\left.\mathrm{F} \mathrm{g}^{-1}\right)$, a higher energy density $\left(E\right.$ in $\left.\mathrm{W} \mathrm{h} \mathrm{kg}^{-1}\right)$, and a higher power density $\left(P\right.$ in $\left.\mathrm{kW} \mathrm{kg}^{-1}\right)$ as compared to the other studied SAILs, [ $\left.\mathrm{P}_{4,4,4,4}\right][\mathrm{EHS}],\left[\mathrm{P}_{6,6,6,14}\right][\mathrm{EHS}]$ and $\left[\mathrm{N}_{8,8,8,8}\right]$ [EHS] (from previous our study) at a temperature range from 253 to $373 \mathrm{~K}$. The

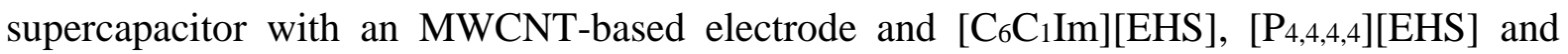
$\left[\mathrm{P}_{6,6,6,14]}[\mathrm{EHS}]\right.$ as electrolytes showed a specific capacitance of 148, 90 and $47 \mathrm{~F} \mathrm{~g}^{-1}$ (at the scan rate of $2 \mathrm{mV} \mathrm{s}^{-1}$ ) with an energy density of 82, 50 and $26 \mathrm{~W} \mathrm{~h} \mathrm{~kg}^{-1}$ (at $2 \mathrm{mV} \mathrm{s}^{-1}$ ), respectively, all at $298 \mathrm{~K}$. For latter three SAILs, the temperature effect can be seen by a two to three-fold increase in the specific capacitance of the cell and the energy density values: 290 , 198 and $114 \mathrm{~F} \mathrm{~g}^{-1}$ (at $2 \mathrm{mV} \mathrm{s}^{-1}$ ) and 161, 110 and $63 \mathrm{Wh} \mathrm{kg}^{-1}$ (at $2 \mathrm{mV} \mathrm{s}^{-1}$ ), respectively, at 373 $\mathrm{K}$. The solution resistance $\left(R_{s}\right)$, charge transfer resistance $\left(R_{c t}\right)$, and equivalent series resistance (ESR) also decreased with an increase in temperature for all SAILs in this study. These new SAILs can potentially be used for high-temperature electrochemical applications, such as supercapacitors for high energy storage due to a reasonably high specific capacitance and enhanced energy and power density, and wider ECWs as compared to molecular organic and
\end{abstract}


aqueous electrolytes. Specifically, $\left[\mathrm{C}_{6} \mathrm{C}_{1} \mathrm{Im}\right][\mathrm{EHS}]$ and $\left[\mathrm{P}_{4,4,4,4}\right][\mathrm{EHS}]$, are the best candidates among other "EHS"-based SAILs in this and our previous study, as electrolytes in supercapacitors.

Keywords: Non-halogenated ionic liquids; Surface-active ionic liquids; Conductivity; Specific capacitance; Electric energy density; Electric power density; MWCNT-based supercapacitors

\section{Introduction}

Ionic liquids (ILs) have been the topic of immense interest as an electrolyte for energy storage devices due to their unique properties, such as low volatility, non-flammability, and high thermal and chemical stability, along with a high electrochemical stability at ambient and elevated temperatures. ${ }^{1-6}$ Among many different classes of ionic liquids, quaternary aprotic room temperature ILs (RTILs) are special due to their high hydrophobicity and thermalelectrochemical stability. The most common quaternary ionic liquids consist of ammonium or phosphonium cations with non-branched alkyl side chains of different length. Usually, these RTILs are highly viscous with a low electrical conductivity at room temperature due to a large molecular size of their cations and a low ionicity, because of formation of hydrophobically aggregated nanoscale domains. ${ }^{7-11}$ However, the challenge with a high viscosity can be tackled with fine-tuning of chemical moieties in both cationic and anionic components of ILs, for example, by changing lengths and branching of alkyl groups, to make RTILs more useful as electrolytes in energy storage devices. Few studies on ammonium and phosphonium cationbased ILs with common anions like bis(trifluoromethanesulfonyl)imide, [NTf $]^{-}$, or bis(fluorosulfonyl)imide, [FSI]', have shown a promising performance of these halogenated RTILs as electrolytes with a low viscosity and a three-four fold larger electrochemical potential window (ECW) as compared to ECWs of molecular organic and standard $\mathrm{KOH}(\mathrm{aq})$ and $\mathrm{H}_{2} \mathrm{SO}_{4}(\mathrm{aq})$ based electrolytes. ${ }^{12}$ However, due to high costs and the presence of halides, the use of halogenated RTILs is rather limited as electrolytes in supercapacitors. ${ }^{13-15}$ Halogen containing anions are prone to hydrolysis giving rise to halide anions. The halides such as $\mathrm{F}^{-}$ and $\mathrm{Br}^{-}$may result in dealkylation reactions of phosphonium, ammonium and imidazolium cations and do reduce the electrochemical stability of ionic liquids by their anodic oxidation at a rather low electrical potential. ${ }^{2}$ 
The use of ILs in supercapacitors as electrolytes or components of electrolytes is a topic of research interest. ${ }^{12,16,17}$ Supercapacitors have already emerged as electrical energy storage devices and have drawn a significant attention of the scientific community due to their high energy and power density, safety (a low risk of explosion at high temperatures as happens for organic electrolytes $)^{18}$ and long-term recyclability and stability. The efficiency of the capacitor primarily depends on the electrode material used, and the operating potential voltage determined by the ECW of the electrolyte. Intriguingly, ionic liquids exhibit interesting properties near charged surfaces that determine the performance of energy devices. In fact, recent experimental and theoretical evidence has shown the formation of an electric double layer (EDL) structure in capacitors near charged electrodes. ${ }^{16,19-21}$ ILs in the EDL behave differently when compared with aqueous and organic (molecular) electrolytes due to specific ion ordering in ionic liquids. ${ }^{22-24}$ Mao et al. have recently explored the electro-capacitive characteristics and EDL nanostructures of surface-active ILs (SAILs). ${ }^{16}$ SAILs can be considered as an important class of ILs since they form stable nanostructures on the hydrophobic electrode surfaces. SAILs are amphiphilic molecules with polar head groups and hydrophobic tails that enable them to form stable nanostructures, unlike non-amphiphilic ILs (NAILs). Nanostructures formed by NAILs are typically smaller and less stable (less ordered) than those formed by SAILs. ${ }^{16,19,25}$ Therefore, SAILs can be used as electrolytes or components of electrolytes in supercapacitors and batteries to operate under a wider range of temperatures. ${ }^{12,16} \mathrm{~A}$ more thorough investigation of SAILs may increase the traditional understanding of ILs in electrochemistry. There is very little known about the SAILs and, to the best of our knowledge, few studies performed on this new class of ionic liquids, which comprise a surface-active anion like 1,4-bis(2-ethylhexoxy)-1,4-dioxobutane-2-sulfonate $(\mathrm{AOT})^{16}$ and 2-ethylhexyl sulfate ${ }^{12}$ as electrolytes or as components of electrolytes in supercapacitors.

While turning to their practical applications, the applied voltage and operating temperature range are of great importance for the construction of supercapacitor devices. High viscosity and low ionic conductivity are typically responsible for an increase in the internal resistance in capacitors. The chemical structure of the ions affects the formation of the electrical double layer (EDL), which may also deteriorate the capacitance of supercapacitors. Therefore, to increase the performance of supercapacitors, in particular, to enhance their energy and power density, a wide operating ECW and a wide operating temperature interval of electrolytes is required. In addition, an appropriate selection of the chemical structure of the constituent ions 
is desired to enhance the interaction between the electrolyte and electrode surfaces to facilitate the formation of stable EDLs and to increase the specific capacitance of the device. Temperature-dependent electrode-electrolyte interactions combined with a wide operating ECW are important parameters to consider to augment the double-layer capacitance of the supercapacitors.

The present study is a continuation of our recent work on a novel SAIL, namely, tetraalkylammonium 2-ethylhexyl sulfate, $\left[\mathrm{N}_{8,8,8,8}\right][\mathrm{EHS}] .{ }^{12}$ Here, we explore novel SAILs, which contain the same surface-active anion, 2-ethylhexyl sulfate ([EHS $]^{-}$) and a range of different phosphonium and imidazolium cations, such as tetrabutylphosphonium $\left(\left[\mathrm{P}_{4,4,4,4}\right]^{+}\right)$, trihexyl(tetradecyl)phosphonium $\left(\left[\mathrm{P}_{6,6,6,14}\right]^{+}\right)$and 1-methyl-3-hexylimidazolium $\left(\left[\mathrm{C}_{6} \mathrm{C}_{1} \mathrm{Im}\right]^{+}\right)$ as potential electrolytes in supercapacitors. $[\mathrm{EHS}]^{-}$is an amphiphilic anion comprising of a polar and charged sulfate group and a non-polar and branched alkyl group with eight aliphatic carbons (see Figure 1). Due to these distinct polar and non-polar domains, [EHS]-based ILs can self-assemble into nanostructures. ${ }^{26,} 27$ Moreover, non-halogenated and surface-active alkylsulfate anions are environmentally benign, cheap and already widely used in soaps, shampoo and detergents. These non-halogenated ILs are non-toxic and more readily biodegradable compared to the other, unfortunately, already widely used in electrochemical applications, halide-containing ionic liquids. The latter ILs are metal halide complexes with $\left[\mathrm{PF}_{6}\right]^{-}$(widely used as $\mathrm{Li}\left[\mathrm{PF}_{6}\right]$ in lithium ion batteries $(\mathrm{LIBs})$ ), $\left[\mathrm{BF}_{4}\right]^{-},\left[\mathrm{NTf}_{2}\right]^{-}$and $[\mathrm{OTf}]^{-}$, which are moisture-sensitive, prone to hydrolysis, corrosive to metals and, which require special expensive lines in production. ${ }^{2,28-30}$

In this work, we report on the performance of neat $\left[\mathrm{P}_{4,4,4,4}\right][\mathrm{EHS}],\left[\mathrm{P}_{6,6,6,14}\right][\mathrm{EHS}]$ and $\left[\mathrm{C}_{6} \mathrm{C}_{1} \mathrm{Im}\right][\mathrm{EHS}]$ as electrolytes in capacitors with multi-walled carbon nanotubes (MWCNT) as an electrode material tested in different electrochemical experiments at different temperatures. MWCNT were chosen in combination with SAILs, because of their specific properties, such as their high electrical conductivity, distinctive charge transfer capability, high electrochemical stability, high electrolyte accessibility, and double-layer capacitor behaviour. ${ }^{31-34}$ The electrochemical performance of studied here SAILs as electrolytes is also compared with that of the previously reported SAIL, $\left[\mathrm{N}_{8,8,8,8}\right][\mathrm{EHS}]$, and its binary $50 \mathrm{wt} \%$ mixture with acetonitrile and with $6 \mathrm{M} \mathrm{KOH}(\mathrm{aq})$ as electrolytes in MWCNT-based supercapacitors in the same temperature range. ${ }^{12}$ We showed that using SAILs as electrolytes, one could achieve improved specific capacitance and a high energy and power density, 
particularly, at elevated temperatures up to $373 \mathrm{~K}$ and with a good cycling stability of the MWCNT-based supercapacitor.

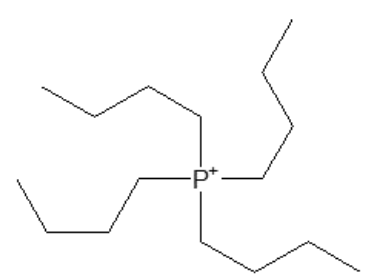

$\left[\mathbf{P}_{4,4,4,4}\right]^{+}$

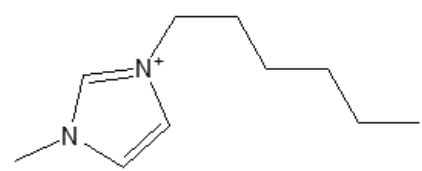

$\left[\mathrm{C}_{6} \mathrm{C}_{1} \mathrm{Im}\right]^{+}$

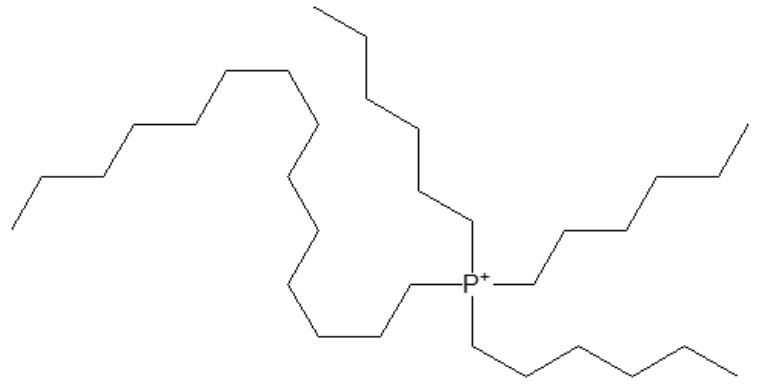

$\left[\mathbf{P}_{6,6,6,14]^{+}}\right.$

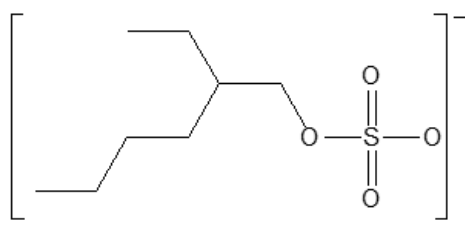

[EHS]

Figure 1. Chemical structures of tetrabutylphosphonium, $\left[\mathrm{P}_{4,4,4,4}\right]^{+}$, trihexyl(tetradecyl)phosphonium, $\left[\mathrm{P}_{6,6,6,14}\right]^{+}$, and 1-methyl-3-hexylimidazolium, $\left[\mathrm{C}_{6} \mathrm{C}_{1} \mathrm{Im}\right]^{+}$, cations and the 2-ethylhexyl sulfate, [EHS]', anion.

\section{Experimental Section}

\section{Chemicals and Materials}

Tetrabutylphosphonium chloride solution, $\left[\mathrm{P}_{4,4,4,4}\right][\mathrm{Cl}](50 \%$ solution in water) was purchased from CYTEC, trihexyl(tetradecyl)phosphonium chloride, $\left[\mathrm{P}_{6,6,6,14}\right][\mathrm{Cl}]$, and 1-methyl-3hexylimidazolium bromide, $\left[\mathrm{C}_{6} \mathrm{C}_{1} \mathrm{Im}\right][\mathrm{Br}]$, were purchased from Solvionic. Sodium 2ethylhexyl sulfate $(50 \%$ solution in water) was purchased from Sigma-Aldrich. Dichloromethane from VWR was used as received. All the materials were not additionally purified before the metathesis reactions.

For the electrode material, multi-walled carbon nanotubes (MWCNTs), activated carbon, and polyvinyl alcohol (PVA) were purchased from Sigma-Aldrich and used as received without further purification.

Synthesis and Characterisation of SAILs 
The final product, $\left(\left[\mathrm{P}_{4,4,4,4}\right][\mathrm{EHS}],\left[\mathrm{P}_{6,6,6,14}\right][\mathrm{EHS}]\right.$ and $\left.\left[\mathrm{C}_{6} \mathrm{C}_{1} \mathrm{Im}\right][\mathrm{EHS}]\right)$ was prepared by the ion exchange (metathesis) reactions between a starting salt $\left(\left[\mathrm{P}_{4,4,4,4}\right][\mathrm{Cl}],\left[\mathrm{P}_{6,6,6,14}\right][\mathrm{Cl}]\right.$ and $\left[\mathrm{C}_{6} \mathrm{C}_{1} \mathrm{Im}\right][\mathrm{Br}]$, respectively) and $[\mathrm{Na}][\mathrm{EHS}]$ in dichloromethane (DCM) at room temperature. The corresponding SAIL was prepared by adding the sodium salt of [EHS] $]^{-}(1.1 \mathrm{mmol})$ to the stirred solution of a starting chloride or bromide salt of cations used in this study (1 mmol) in DCM. The reaction mixture was stirred for 48 hours at ambient pressure (ca. 1 bar) and at room temperature (ca. $295 \mathrm{~K}$ ). To remove the excess of the reagent ([Na][EHS] salt) from the final product, the reaction mixture was then washed with distilled water three times. The excess water and DCM was removed using a rotary evaporator. To further remove traces of DCM and water, the final products (SAILs) were kept in a vacuum oven at $353 \mathrm{~K}$ for 4 days. Both SAILs identity and purity were checked by solution ${ }^{1} \mathrm{H},{ }^{13} \mathrm{C}$ and ${ }^{31} \mathrm{P}$ (for phosphonium-based SAILs) NMR spectroscopy. Residual content of $\mathrm{Br}^{-}, \mathrm{Cl}^{-}$and $\mathrm{Na}^{+}$ions (recommended levels of $<500$ ppm) was analysed using Inductive Coupled Plasma Atomic Emission Spectroscopy (ICPAES) by ALS Scandinavia, Luleå. Solution NMR spectra (see Figures S1-S8) and results of the elemental analysis (see Table S1) are provided in the Electronic Supplementary Information (ESI).

\section{Nuclear Magnetic Resonance (NMR) Spectroscopy}

Solution ${ }^{1} \mathrm{H},{ }^{13} \mathrm{C}$ and ${ }^{31} \mathrm{P}$ NMR spectra of SAILs (in $\mathrm{CDCl}_{3}$ with $0.03 \% \mathrm{v} / \mathrm{v}$ TMS) were obtained using a $400 \mathrm{MHz}$ Bruker Avance III NMR spectrometer (Bruker BioSpin AG, Fällanden, Switzerland) with an Aeon 9.4 T zero-helium boil-off superconducting magnet and 10 or $5 \mathrm{~mm}$ probes for liquids. Working frequencies were $400.27 \mathrm{MHz}$ for ${ }^{1} \mathrm{H}, 100.64 \mathrm{MHz}$ for ${ }^{13} \mathrm{C}$ and 162.000 MHz for ${ }^{31} \mathrm{P}$. Proton decoupling pulse sequence WALTZ-16 was used for ${ }^{13} \mathrm{C}$ NMR. For ${ }^{1} \mathrm{H} 90^{\circ}$-pulse duration and the recycling delay were $9 \mu$ s and $1 \mathrm{~s}$, respectively. For ${ }^{13} \mathrm{C}, 30^{\circ}$ pulse duration of $9 \mu \mathrm{s}$ and a recycling delay of $3 \mathrm{~s}$ were used to minimize the signal saturation effects due to the longer $\mathrm{T}_{1}$ relaxation time of ${ }^{13} \mathrm{C}$ sites. For the same reason, ${ }^{31} \mathrm{P} 30^{\circ}$-pulse duration and the recycling delay were $25 \mu \mathrm{s}$ and $2 \mathrm{~s}$, respectively. Bruker "Topspin-3.5" software was used for NMR data processing.

Thermogravimetric Analysis (TGA)

TGA was performed using a Perkin Elmer TGA 8000 instrument with about $3 \mathrm{mg}$ of a SAIL sample from $303 \mathrm{~K}$ to $973 \mathrm{~K}$ at a rate of $10 \mathrm{~K} \mathrm{~min}^{-1}$ under nitrogen gas flow of $20 \mathrm{~mL} \mathrm{~min}^{-1}$.

Differential Scanning Calorimeter (DSC) 
A Perkin Elmer DSC 6000 instrument was used to measure melting, crystallisation and glass transition temperatures for all SAILs in this study. For these experiments, about $4 \mathrm{mg}$ of a SAIL sample was packed in an aluminium pan. Heating and cooling DSC scans were recorded from 213 to $373 \mathrm{~K}$ at a rate of $10 \mathrm{~K} \mathrm{~min}^{-1}$ for all samples. To maintain a dry environment inside the sample chamber, nitrogen gas was supplied at a flow of $20 \mathrm{~mL} \mathrm{~min}^{-1}$.

\section{Pellet Formation}

A stainless-steel pellet die was used for pellet formation. The electrode used for the current study mainly contains the MWCNTs, activated carbon, and PVA as a binder in a 7:2:1 ratio by weight, respectively. A powder composed of these three compounds was carefully mixed using a pestle and a mortar. Then pellets were pressed at varying pressures $(300-1000 \mathrm{kPa})$ by a manual press. Pellets were $10 \mathrm{~mm}$ in diameter. The sample weight of a pellet was ca. $10 \mathrm{mg}$. Glass microfiber Whatman filter paper was used as a separator.

\section{Electrochemical Measurements}

All electrochemical measurements were performed using a Metrohm Autolab (PGSTAT302N) electrochemical workstation, with the FRA32M module for impedance measurements. Conductivity of electrolytes used in this study (neat SAILs: [P $\left.\mathrm{P}_{4,4,4,4}\right][\mathrm{EHS}],\left[\mathrm{P}_{6,6,6,14}\right]$ [EHS] and $\left[\mathrm{C}_{6} \mathrm{C}_{1} \mathrm{Im}\right][\mathrm{EHS}]$ ) was measured using ca. $70 \mu \mathrm{L}$ of a SAIL in a TSC 70 closed cell (RHD instruments) in the temperature range between 253 and $373 \mathrm{~K}$. The supercapacitor measurements were carried out in a TSC battery cell, which was mounted on the Microcell HC stand with a Peltier element to control the sample temperature with a precision of $\pm 1 \mathrm{~K}$ in a temperature range from 269 to $373 \mathrm{~K}$. Prior to each experiment, two electrodes were polished using a Kemet diamond paste $(0.25 \mu \mathrm{m})$. For data processing, Nova 2.1.4 software was used. ECWs for the studied SAILs were determined by cyclic voltammetry (CV) at $293 \mathrm{~K}$ using a two-electrode cell assembly with a glassy carbon working electrode and a platinum cup as the counter electrode at the scan rate $100 \mathrm{mV} \mathrm{s}^{-1}$. This two-electrode cell assembly was also used to measure the ionic conductivity by electrochemical impedance spectroscopy (EIS). All EIS experiments were performed in the frequency range from $0.01 \mathrm{~Hz}$ to $1 \mathrm{MHz}$ with an alternating current (AC) amplitude of $10 \mathrm{mV}$. The cell was thermally equilibrated prior to each measurement for at least $10 \mathrm{~min}$.

An MWCNT-supercapacitor device contained two pellets with a filter paper sandwiched between them as a separator (see Figure 2). The filter paper was kept in a SAIL electrolyte for 24 hours before measurements were taken. The cell consists of nickel-plated copper lower and 
upper current collectors with an average contact area of $8 \mathrm{~mm}$ in diameter each (the TSC battery cell). Therefore, an active surface area of pellets was also $8 \mathrm{~mm}$ in diameter. A glass microfiber Whatman filter paper of $12 \mathrm{~mm}$ in diameter was used as a separator. The cell was packed with a screw cap, and the contact pressure was adjusted to $40.7 \mathrm{kPa}$ using a gold-plated spring with a spring constant of $2.3 \mathrm{~N} \mathrm{~mm}^{-1}$.

The electrochemical performance of the supercapacitor was measured in a two-electrode cell assembly at various temperatures. The electrochemical measurements were carried out using a TSC battery cell assembly as shown in Figure 2.

In the electrochemical tests, the supercapacitor was activated by $\mathrm{CV}$ at a lower scan rate, 50 cycles at $5 \mathrm{mV} \mathrm{s}^{-1}$ at $313 \mathrm{~K}$ for $\left[\mathrm{P}_{4,4,4,4}\right]$ [EHS] (see Figure S9 in the ESI) and 25 cycles at $5 \mathrm{mV}$ $\mathrm{s}^{-1}$ at $333 \mathrm{~K}$ for $\left[\mathrm{C}_{6} \mathrm{C}_{1} \mathrm{Im}\right][\mathrm{EHS}]$ (see Figure $\mathbf{S 1 0}$ in the ESI). Later, electrochemical impedance spectroscopic (EIS) measurements were performed followed by CVs at different scan rates and GCD experiments. At each temperature before recording CVs at different scan rates, 5 cycles were recorded at $2 \mathrm{mV} \mathrm{s}^{-1}$ for further activation of the electrode. Thereafter, $\mathrm{CVs}$ were recorded at different scan rates (from 2 to $100 \mathrm{mV} \mathrm{s}^{-1}$ ) and at different temperatures interrupted by EIS measurements at each temperature. GCD tests were performed in the electric potential range from -2 to $+2 \mathrm{~V}$ for $\left[\mathrm{P}_{4,4,4,4]}[\mathrm{EHS}]\right.$ and $\left[\mathrm{C}_{6} \mathrm{C}_{1} \mathrm{Im}\right][\mathrm{EHS}]$ and from -2.5 to $2.5 \mathrm{~V}$ for $\left[\mathrm{P}_{6,6,6,14}\right][\mathrm{EHS}]$ at different current densities: 0.07, 0.11, and $0.14 \mathrm{~A} \mathrm{~g} \mathrm{~g}^{-1}$. The electrochemical measurements were performed for all the studied SAILs in the electric potential range from -2 to $+2 \mathrm{~V}(\mathrm{ECW}=4 \mathrm{~V})$. Additionally, the performance of supercapacitor cells was also explored in the electric potential range from -2.5 to $+2.5 \mathrm{~V}(\mathrm{ECW}=5 \mathrm{~V})$ for $\left[\mathrm{P}_{6,6,6,14}\right][\mathrm{EHS}]$ (at 298, 313,333 and $373 \mathrm{~K}$ ) and [P4,4,4, ][EHS] (at 298 and $373 \mathrm{~K}$ )

The specific capacitance of the material $\left(C_{\text {elec }}\right.$ in $\left.\mathrm{F} \mathrm{g} \mathrm{g}^{-1}\right)$, the energy density $\left(E\right.$ in $\left.\mathrm{W} \mathrm{h} \mathrm{kg}^{-1}\right)$ and the power density $\left(P\right.$ in $\mathrm{kW} \mathrm{kg}^{-1}$ ) of the supercapacitor cell were calculated from the $\mathrm{CV}$ curves ${ }^{16}$ using Eqs. (1), (2) and (3), respectively as given below:

$$
\begin{aligned}
& C_{\text {elec }}=4 \frac{\int I d V}{m\left(\frac{d V}{d t}\right)} \\
& E=\frac{C_{s p} V^{2}}{2} \times \frac{1000}{3600} \\
& P=\frac{E\left(\frac{d V}{d t}\right)}{V} \times \frac{3600}{1000}
\end{aligned}
$$


where $I$ is current (in A), $d V / d t$ is a scan rate (in $\mathrm{V} \mathrm{s}^{-1}$ ), $m$ is the total weight of the electrode material (in $\mathrm{g}$ ), $V$ is the applied cell potential (in $\mathrm{V}$ ), $\int I d V$ are total areas (both positive and negative but added as modulus) identified by $I(V)$ curves in the $\mathrm{CV}$ plots, and $C_{\mathrm{sp}}$ is the capacitance of the supercapacitor device $\left(C_{\mathrm{sp}}=C_{\text {elec }} / 4\right)$.

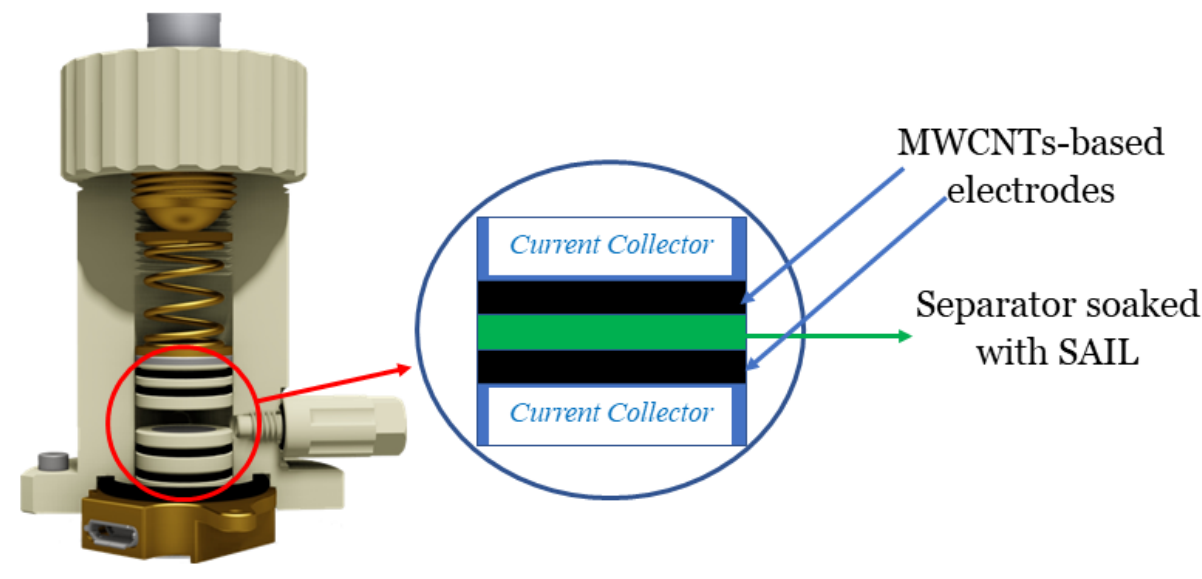

Figure 2. A setup used in electrochemical measurements for a supercapacitor cell with MWCNT-based electrodes and neat $\left[\mathrm{P}_{4,4,4,4}\right][\mathrm{EHS}],\left[\mathrm{C}_{6} \mathrm{C}_{1} \mathrm{Im}\right][\mathrm{EHS}]$ and $\left.\left[\mathrm{P}_{6,6,6,14]}\right] \mathrm{EHS}\right]$ as electrolytes. The supercapacitor is yet not placed in the setup.

\section{Results and Discussion}

Electrical Conductivity and Electrochemical Potential Window of SAILs

Electrical conductivity in aprotic ILs originates predominantly from the intrinsic mobility of cations and anions. In the present study on SAILs containing the same 2-ethylhexyl sulfate anion but different cations, we explore major structural impacts of cations on the electrical conductivity and electrochemical stability of these SAILs. The ionic conductivity of neat SAILs, $\left[\mathrm{C}_{6} \mathrm{C}_{1} \mathrm{Im}\right][\mathrm{EHS}],\left[\mathrm{P}_{4,4,4,4}\right][\mathrm{EHS}]$ and $\left[\mathrm{P}_{6,6,6,14}\right][\mathrm{EHS}]$ was measured using GC-electrodes in the temperature range from 253 to $373 \mathrm{~K}$. Measurements at each temperature point were performed in duplicate, first, during sample heating and, then, during cooling. The conductivity data points obtained during sample heating and cooling were close to each other (see Figure 3). The electrical conductivity of $\left[\mathrm{C}_{6} \mathrm{C}_{1} \mathrm{Im}\right][\mathrm{EHS}]$ was found to be higher compared to that of $\left[\mathrm{P}_{4,4,4,4}\right][\mathrm{EHS}]$ and $\left[\mathrm{P}_{6,6,6,14]}[\mathrm{EHS}]\right.$ in the whole temperature range studied. For example, at 298 $\mathrm{K}$, conductivities are $73.19,18.74$ and $5.44 \mu \mathrm{S} \mathrm{cm}^{-1}$ for $\left[\mathrm{C}_{6} \mathrm{C}_{1} \mathrm{Im}\right][\mathrm{EHS}],\left[\mathrm{P}_{4,4,4,4}\right][\mathrm{EHS}]$ and $\left[\mathrm{P}_{6,6,6,14}\right][\mathrm{EHS}]$, respectively, and increased ca. 20-40 fold for these three SAILs at $373 \mathrm{~K}$, up 
to $1.62,0.68$ and $0.15 \mathrm{mS} \mathrm{cm}{ }^{-1}$, respectively. The electrical conductivity in ionic liquids is mainly dependent on the ionicity (the number of mobile ions available in the system) and viscosity of ILs. Therefore, a significant difference in the electrical conductivity of the three SAILs in this study, particularly, at near-room temperatures can be explained by differences in viscosity and in formation of ionic complexes due to specific electrostatic and van der Waals interactions leading to aggregation and ion-pairing. These factors result in both a low ionicity and a low ionic mobility, thus, to a low electrical conductivity in SAILs. On the other hand, upon an increase in temperature, viscosity of ILs decreases almost exponentially. Therefore, both the ion mobility and the electrical conductivity do increase abruptly with temperature. Despite a low electrical conductivity at ambient temperatures, this class of SAILs can yet be considered as a good electrolyte for supercapacitors, when compared to organic- and aqueousbased electrolytes due to a two-four fold larger ECWs of SAILs (see Figure 4). The ECW of an electrolyte plays a crucial role in the supercapacitors, because the electric energy density of these devices depends on the square of the operating voltage (see Eq. (2)). Therefore, a larger amount of energy can be stored in these devices with SAILs as electrolytes compared to "standard" organic- and aqueous-based electrolytes.

CVs recorded at the scan rate of $100 \mathrm{mV} \mathrm{s}^{-1}$ and at $298 \mathrm{~K}$ for different electric potential windows revealed the electrochemical stability (no redox peaks in the CV curves) with applied electric potential from +2 to $-2 \mathrm{~V}$ for phosphonium-based SAILs, [ $\left.\mathrm{P}_{6,6,6,14}\right]$ [EHS] and

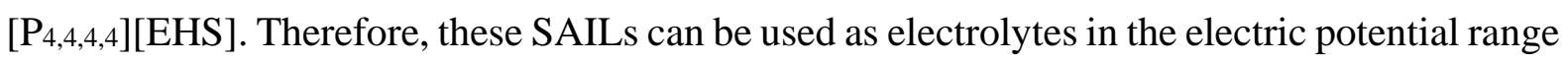
from -2 to $+2 \mathrm{~V}$. On the other hand, two small peaks around $-0.5 \mathrm{~V}$ and $+1.3 \mathrm{~V}$ were observed in the $\mathrm{CV}$ curves for $\left[\mathrm{C}_{6} \mathrm{C}_{1} \mathrm{Im}\right][\mathrm{EHS}]$ (see Figure 4). This might be because of the carbene formation in neat alkylsulfate-based ILs as reported previously. ${ }^{35}\left[\mathrm{C}_{6} \mathrm{C}_{1} \mathrm{Im}\right][\mathrm{EHS}]$ also shows some redox peaks in the supercapacitor device at elevated temperatures (see Figure S12 in ESI). These processes are, however, reversible and can contribute to the enhancement of the specific capacitance in the form of "pseudocapacitance". Phosphonium-based ILs are shown to possess a higher electrochemical stability, as compared to the ammonium-based ILs. ${ }^{36}$ Indeed, $\left[\mathrm{P}_{6,6,6,14}\right][\mathrm{EHS}]$ and $\left[\mathrm{P}_{4,4,4,4}\right][\mathrm{EHS}]$ in this study are electrochemically stable even between -2.5 and $+2.5 \mathrm{~V}$, thus, their ECWs are at least $5 \mathrm{~V}$ at near-room temperatures. 

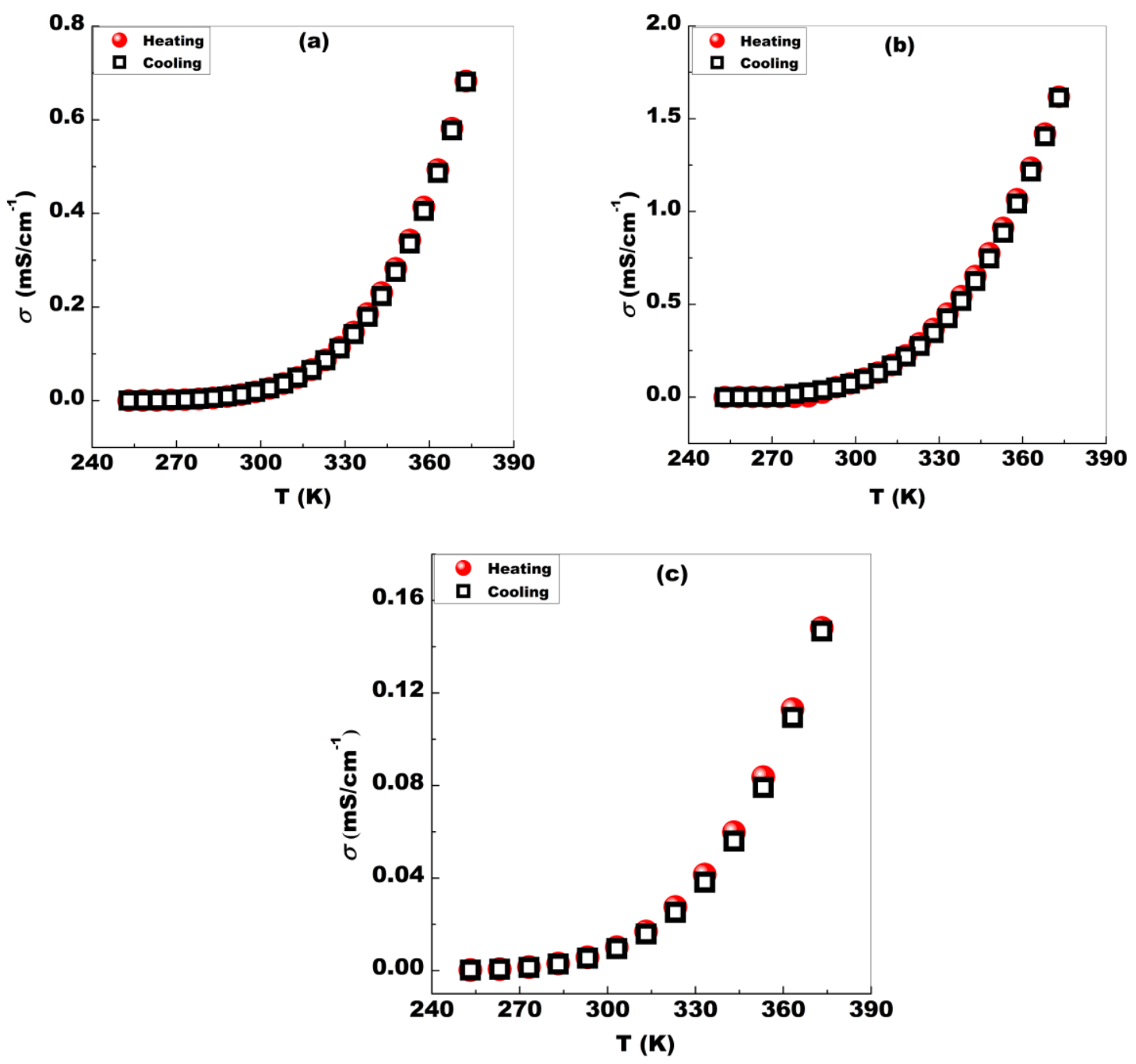

Figure 3. Comparative (heating - red circles, cooling - black open squares) electrical conductivity data of neat $\left[\mathrm{P}_{4,4,4,4}\right][\mathrm{EHS}](\mathbf{a}),\left[\mathrm{C}_{6} \mathrm{C}_{1} \mathrm{Im}\right][\mathrm{EHS}](\mathbf{b})$ and $\left[\mathrm{P}_{6,6,6,14}\right][\mathrm{EHS}](\mathbf{c})$, on GC electrodes at the AC voltage amplitude of $10 \mathrm{mV}$. 


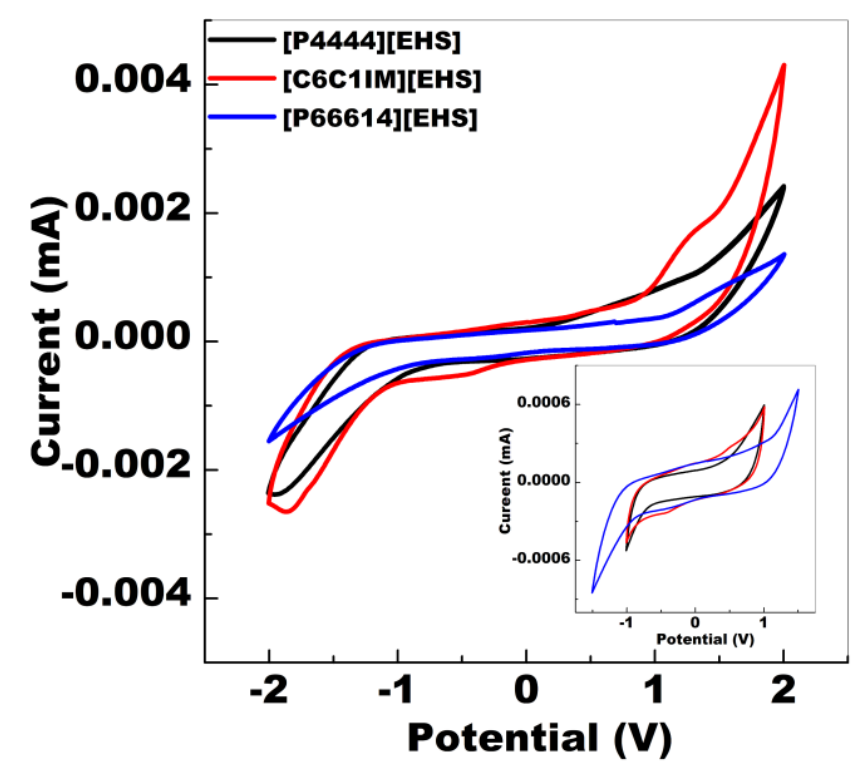

Figure 4. $\mathrm{CV}$ curves (from -2 to $+2 \mathrm{~V}$ ) for neat $\left[\mathrm{C}_{6} \mathrm{C}_{1} \mathrm{Im}\right][\mathrm{EHS}]$ (red), $\left[\mathrm{P}_{4,4,4,4}\right][\mathrm{EHS}]$ (black) and $\left[\mathrm{P}_{6,6,6,14}\right][\mathrm{EHS}]$ (blue) on GC electrodes obtained at the scan rate of $100 \mathrm{mV} \mathrm{s}^{-1}$ and at 298 $\mathrm{K}$. Inset shows $\mathrm{CV}$ curves (from -1 to $+1 \mathrm{~V}$ ) for $\left[\mathrm{P}_{4,4,4,4}\right][\mathrm{EHS}],\left[\mathrm{C}_{6} \mathrm{C}_{1} \mathrm{Im}\right][\mathrm{EHS}]$ and from -1.5 to $+1.5 \mathrm{~V}$ for $\left[\mathrm{P}_{6,6,6,14]}[\mathrm{EHS}]\right.$.

\section{Thermal Characterisation of SAILs by DSC and TGA}

The thermal stability of ILs mainly depends on the structure of constituent ions (cations and anions) and their interionic interactions. Thermal properties of the neat SAILs in this study were examined by the thermal gravimetric analysis (TGA) and differential scanning calorimetry (DSC). The TG plots and DSC traces of the studied SAILs are shown in Figures 5 and 6, respectively. The decomposition temperature $\left(T_{d}\right)$, melting and crystallisation temperatures were measured by TGA and DSC, respectively. The $T_{d}$ of a given IL depends on the inherent stability of the ionic liquid and interactions between their constituent ions. The TG

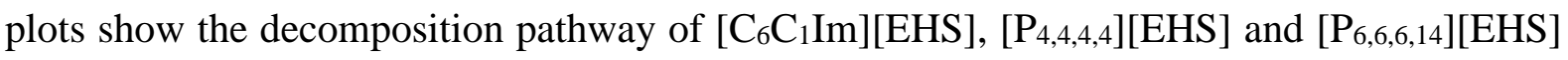
at $10 \mathrm{~K} \mathrm{~min}^{-1}$ (see Figure 5) and degradation temperature values are also reported at different (2, 5 and 10) weight loss \% in Table S2. This is in accordance with other studies, which revealed that imidazolium-based ionic liquids are thermally less stable than phosphoniumbased ILs (with the same anions), but more thermally stable than the corresponding ammonium-based ionic liquids. ${ }^{37}$ Differences in the thermal properties of SAILs studied here are mainly coming from the cationic part, as the same anion was used. A DSC trace of $\left[\mathrm{C}_{6} \mathrm{C}_{1} \mathrm{Im}\right][\mathrm{EHS}]$ in Figure $\mathbf{6}$ shows a couple of thermal events during heating and cooling scans. 
During the heating cycle at $10 \mathrm{~K} \mathrm{~min}^{-1}$ from $213 \mathrm{~K}$, two thermal events take place at $257 \mathrm{~K}$ (crystallisation) and $298 \mathrm{~K}$ (melting), while for the cooling cycle only one event was observed at $265 \mathrm{~K}$, which corresponds to crystallisation of this SAIL. The other two SAILs in this study, show no distinct thermal events in the temperature range from 213 to $373 \mathrm{~K}$ (see Figure 6). Therefore, the latter two SAILs can be used as electrolytes in a wider range of temperatures, compared to $\left[\mathrm{C}_{6} \mathrm{C}_{1} \mathrm{Im}\right][\mathrm{EHS}]$. The heating and cooling ramp in DSC scans was chosen $10 \mathrm{~K}$ $\min ^{-1}$. All further heating and cooling cycles are reproducible and similar to the first heating and second cooling cycles that additionally confirms a high purity of SAILs used in this study.

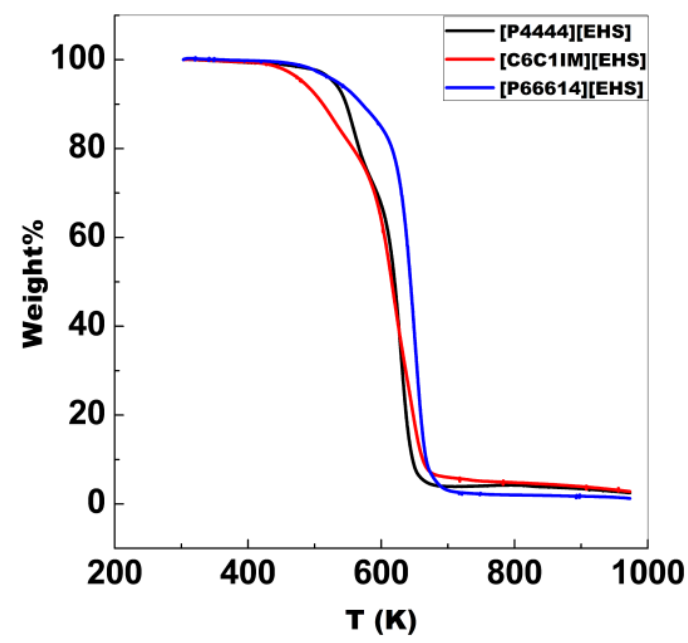

Figure 5. TG-plots of $\left[\mathrm{C}_{6} \mathrm{C}_{1} \mathrm{Im}\right][\mathrm{EHS}]$ (red), $\left[\mathrm{P}_{4,4,4,4}\right][\mathrm{EHS}]$ (black) and $\left[\mathrm{P}_{6,6,6,14}\right][\mathrm{EHS}]$ (blue) measured with the heating rate of $10 \mathrm{~K} \mathrm{~min}^{-1}$ in the temperature range from 303 to $973 \mathrm{~K}$.

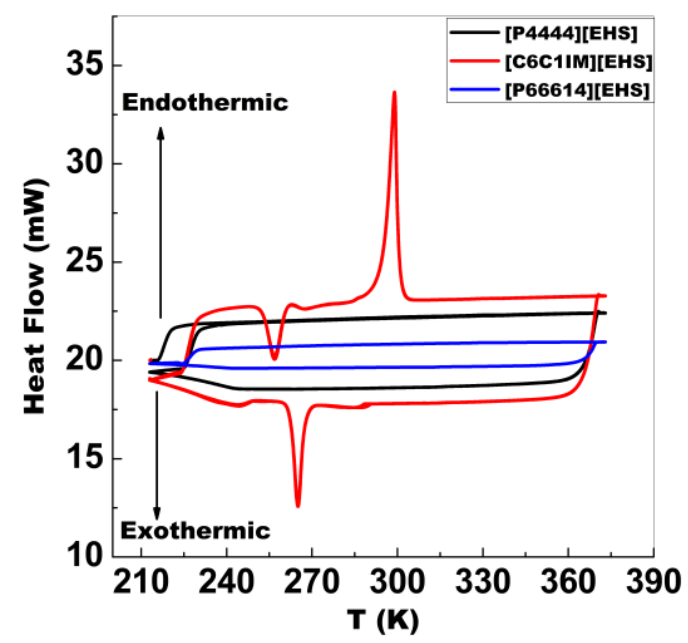

Figure 6. DSC traces for pure SAILs, $\left[\mathrm{P}_{4,4,4,4}\right][\mathrm{EHS}]$ (black), $\left[\mathrm{C}_{6} \mathrm{C}_{1} \mathrm{Im}\right][\mathrm{EHS}]$ (red), and $\left[\mathrm{P}_{6,6,6,14}\right][\mathrm{EHS}]$ (blue) at the heating rate of $10 \mathrm{~K} \mathrm{~min}^{-1}$. 
Therefore, a wide ECW, moderate ionic conductivity, a high thermal and electrochemical stability, and the presence of surface-active anions make these new SAILs as promising candidates for solvent-free electrolytes in high-energy storage devices such as supercapacitors, as will be explored further below.

\section{Supercapacitor Measurements}

Cyclic voltammetry (CV) curves were measured at different temperatures for the MWCNTbased electrode material and SAILs in this study, [P $\left.\mathrm{P}_{4,4,4,4}\right][\mathrm{EHS}],\left[\mathrm{C}_{6} \mathrm{C}_{1} \mathrm{Im}\right][\mathrm{EHS}]$ and

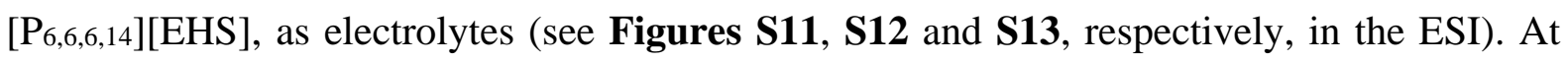
298, 313 and $333 \mathrm{~K}, \mathrm{CV}$ curves measured at low scan rates (2, 5, 10 and $20 \mathrm{mV} \mathrm{s}^{-1}$ ) have characteristic rectangular shapes. However, the shapes are more distorted at higher scan rates (at 50 and $100 \mathrm{mV} \mathrm{s}^{-1}$ ). Interestingly, at even higher temperatures, 353 and $373 \mathrm{~K}, \mathrm{CV}$ curves have rectangular shapes at all scan rates in this study that indicates a double-layer type of capacitance of the MWCNT-based supercapacitor with these SAILs. Figure 7 shows variations of the specific capacitance $\left(C_{\text {elec }}\right)$ with the electric potential scan rate for all the studied SAILs at different temperatures. Rectangular CV shapes indicate a good capacitive performance of the capacitor at lower scan rates at 298, 313 and $333 \mathrm{~K}$. The capacitive performance is getting poorer at higher scan rates at these temperatures, but improved for all scan rates at 353 and 373 K. A poor capacitive performance at low temperatures may be ascribed to a low mobility of ions in electrolytes and a slow rearrangement of double layers of SAILs at surfaces of electrodes. In contrary, SAILs in this study show a better performance as electrolytes at high temperatures, when their viscosities decrease and ionic mobilities increase, without any chemical degradation and with a high electrochemical stability. A comparison between three SAILs in this study reveals that at the same experimental conditions of the scan rate, ECW of $4 \mathrm{~V}$ and temperature, $\left[\mathrm{C}_{6} \mathrm{C}_{1} \mathrm{Im}\right][\mathrm{EHS}]$ shows higher specific capacitance values than those for $\left[\mathrm{P}_{4,4,4,4}\right][\mathrm{EHS}]$ and $\left[\mathrm{P}_{6,6,6,14}\right][\mathrm{EHS}]$ in the whole temperature range from 298 to $373 \mathrm{~K}$.

The electric potential span for phosphonium-EHS SAILs can be increased from 4 to $5 \mathrm{~V}$ without any noticeable redox processes in a temperature range from 298 to 373 K: Figure 7d shows the specific capacitance values for a MWCNT/[ $\left.\mathrm{P}_{6,6,6,14}\right][\mathrm{EHS}]$ capacitor and corresponding CV curves are shown in Figure S14 in the ESI. When the ECW was increased from 4 to $5 \mathrm{~V}$, a significant increase in the specific capacitance, by $35-80 \%$, was measured for the MWCNT/[P $6,6,6,14][\mathrm{EHS}]$ system at ECW $=5 \mathrm{~V}$ (see Figure 7d) as compared to $C_{\text {elec }}$ at $\mathrm{ECW}=4 \mathrm{~V}$ (see Figure 7c). However, compared to the other two SAILs in this study, 
$\left[\mathrm{P}_{6,6,6,14][\mathrm{EHS}]}\right.$ has much bulkier trihexyl(tetradecyl)phosphonium cations. Therefore, this SAIL is less appropriate for MWCNT-based electrodes, because charging/discharging and a double-layer capacitive behaviour depend on the pore size of the electrode material and the size of ions in electrolytes. Due to a significantly larger size of $\left[\mathrm{P}_{6,6,6,14}\right]^{+}$, these cations are less prone for adsorption into pores of MWCNTs with a diameter of less than 3-4 nm. ${ }^{38}$ In this our study, SAILs were selected with the [EHS $^{-}$anion of a smaller size as compared to that of anions in previously studied SAILs. ${ }^{16}$ A better performance of the MWCNT/SAILs capacitors was further achieved by the use of less bulky cations, such as $\left[\mathrm{P}_{4,4,4,4}\right]^{+}$and $\left[\mathrm{C}_{6} \mathrm{C}_{1} \mathrm{Im}\right]^{+}$. Indeed,

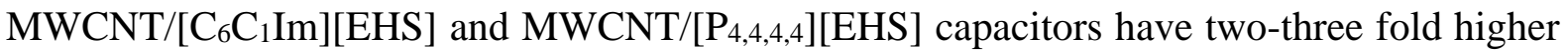
specific capacitance, energy density, and power density values in the whole range of temperatures in this study. Note that SAILs could be used in combination with other high surface area electrode materials to achieve even higher values for the specific capacitance and a better performance of supercapacitor devices (cyclic stability, electrochemical stability of electrolytes, etc. $)^{39-42}$
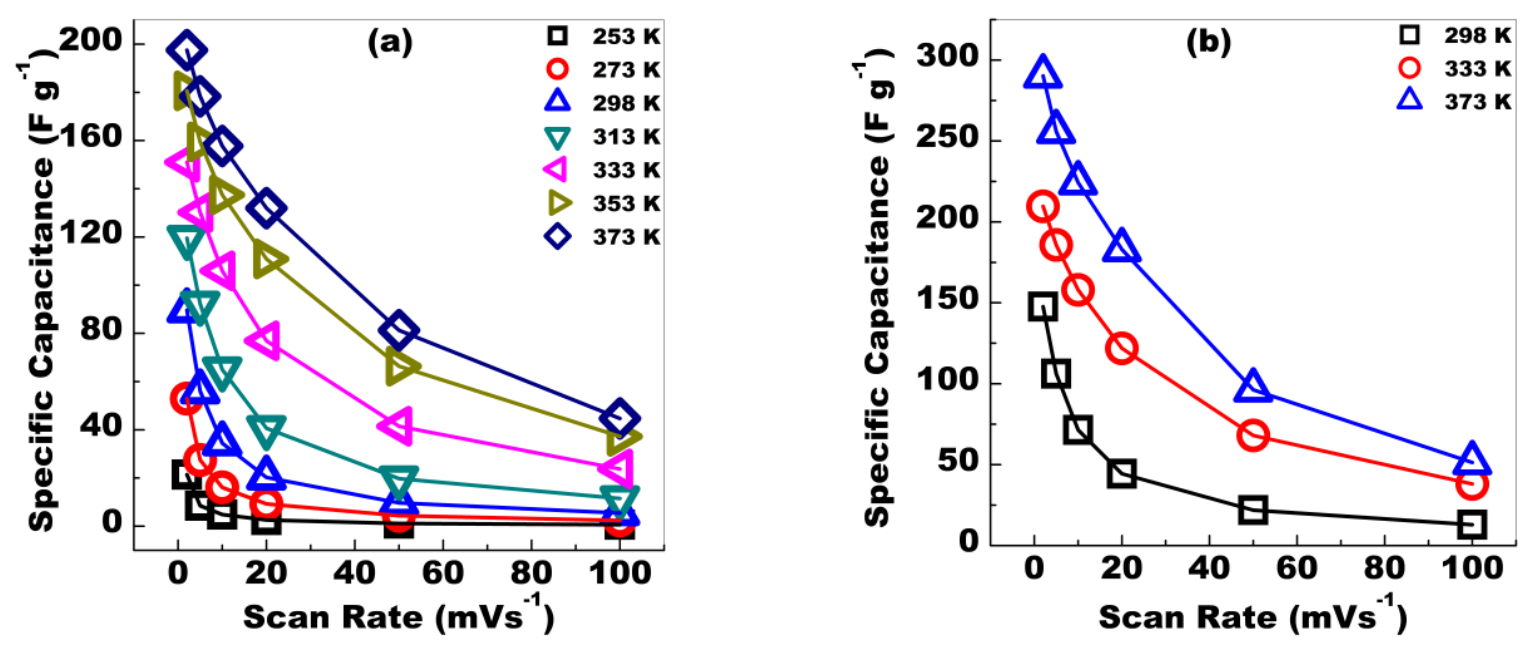

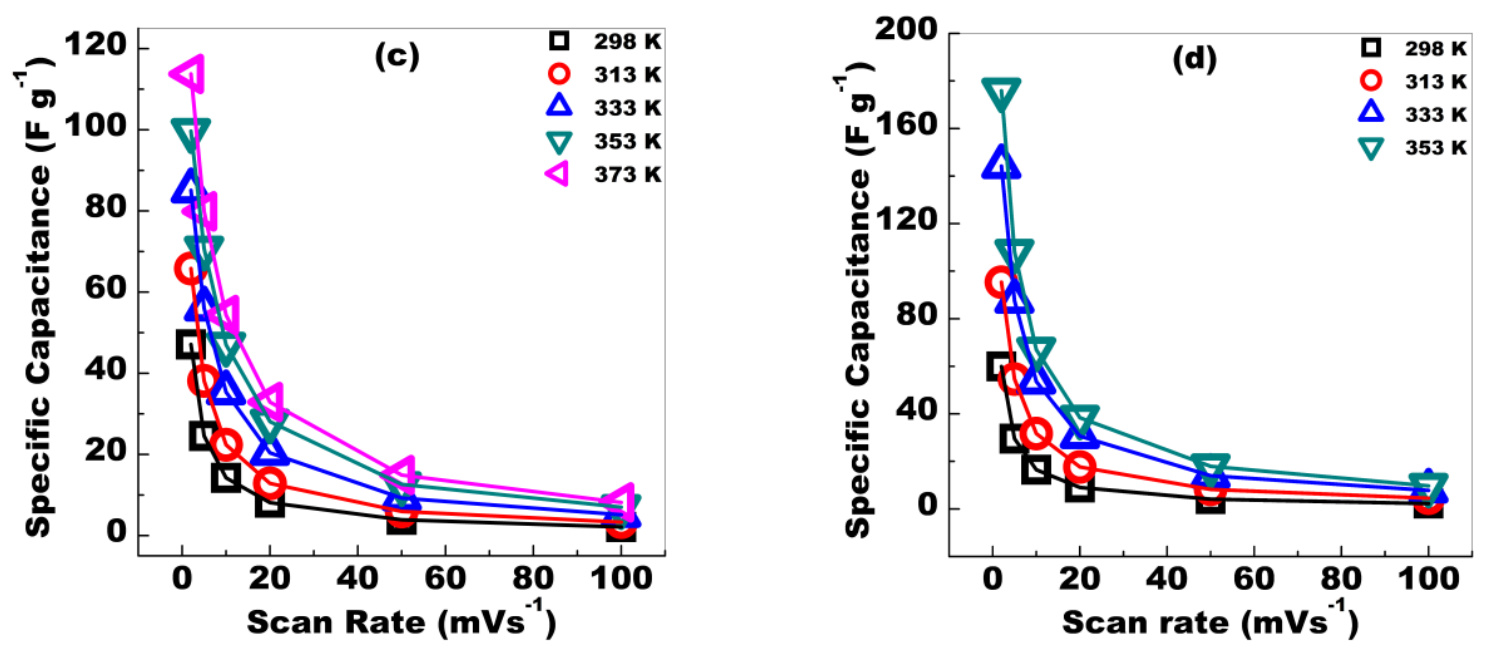

Figure 7. The specific capacitance values at different scan rates in the temperature range from 253 to $373 \mathrm{~K}$ at ECW of $4 \mathrm{~V}$ for $\left[\mathrm{P}_{4,4,4,4}\right][\mathrm{EHS}](\mathbf{a}),\left[\mathrm{C}_{6} \mathrm{C}_{1} \mathrm{Im}\right][\mathrm{EHS}](\mathbf{b})$ and $\left[\mathrm{P}_{6,6,6,14}\right][\mathrm{EHS}](\mathbf{c})$

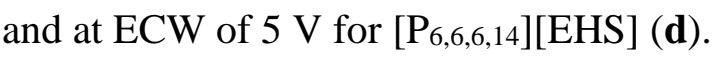

The electrocapacitive performance of the SAILs also depends on their chemical structure as it might alter specific interactions between the SAIL and the electrode surface. A recent study provided an evidence that a SAIL may form stable electric double layers (EDLs) on electrode surfaces. ${ }^{16}$ A characteristic rectangular shape of $\mathrm{CV}$ curves at elevated temperatures and at high scan rates for MWCNTs/SAILs capacitors in this study is an indication of such stable EDL layers formed on MWCNTs that could be one of the reasons for a high specific capacitance of these devices, particularly for SAILs with less bulky cations, such as $\left[\mathrm{C}_{6} \mathrm{C}_{1} \operatorname{Im}\right]^{+}$and $\left[\mathrm{P}_{4,4,4,4}\right]^{+}$. The specific capacitance values of supercapacitor MWCNTs/SAILs cells in this study range from 50 to $150 \mathrm{~F} \mathrm{~g}^{-1}$ at $298 \mathrm{~K}$, which are, actually, significantly higher than those reported in the literature for CNT-based capacitors with RTILs and other types of electrolytes (15-80 F g${ }^{1}$ at ca. $\left.298 \mathrm{~K}\right){ }^{43-46}$

It is interesting to compare shapes of CV curves for capacitors with MWCNTs electrodes and three different electrolytes in this study (see Figures S11, S12 and S13 in the ESI) and their specific capacitance values as a function of scan rates and at different temperatures (see Figure 7). At low scan rates of 2 and $5 \mathrm{mV} \mathrm{s}^{-1}$ and at $\mathrm{T}>313 \mathrm{~K}$, shapes of $\mathrm{CV}$-curves are almost rectangular for all the studied SAILs. However, CV-curves become more and more distorted upon an increase in the scan rate, specifically at $\mathrm{T}<333 \mathrm{~K}$ for capacitors with $\left[\mathrm{P}_{6,6,6,14]}\right.$ [EHS] and $\left[\mathrm{P}_{4,4,4,4]}[\mathrm{EHS}]\right.$ as electrolytes (see Figures S11 and S13 in the ESI) and these distortions are more pronounced at temperatures below $313 \mathrm{~K}$. Interestingly, for $\left[\mathrm{C}_{6} \mathrm{C}_{1} \mathrm{Im}\right][\mathrm{EHS}]$, the 
"rectangular" shape of CV-curves remains almost undistorted up to scan rates of 50 and 100 $\mathrm{mV} \mathrm{s}^{-1}$ at 333 and $373 \mathrm{~K}$, (see Figures S12b and S12c in the ESI). Both shapes of CV curves and the specific capacitance values indicate that $\left[\mathrm{C}_{6} \mathrm{C}_{1} \mathrm{Im}\right][\mathrm{EHS}]$ does perform as a good electrolyte in MWCNTs-based supercapacitors in a wide temperature range from 298 to 373 $\mathrm{K}$, but preferably at temperatures above $333 \mathrm{~K}$. These facts are in a good agreement with previously reported data for SAILs with other types of bulky anions (1,4-bis(2-ethylhexoxy)1,4-dioxobutane-2-sulfonate (AOT)). ${ }^{16}$ This our study suggests that more stable and more mobile EDLs are formed on MWCNTs electrodes for SAILs with less bulky cations $\left(\left[\mathrm{C}_{6} \mathrm{C}_{1} \mathrm{Im}\right]^{+}\right.$ and $\left[\mathrm{P}_{4,4,4,4}\right]^{+}$), compared to SAILs with the same anion [EHS $]^{-}$, but more bulky cations, such as $\left[\mathrm{P}_{6,6,6,14}\right]^{+}$(this study) and $\left[\mathrm{N}_{8,8,8,8}\right]^{+12}$ even at high scan rates and at elevated temperatures ( $\mathrm{T}$ $>333 \mathrm{~K}$ ). For neat SAILs, an increase in temperature facilitates an increase in the mobility of ions, their approach to and reorientation at surfaces of electrodes and, hence, the ability of SAILs to form stable EDLs. The ionic conductivity (see Figure 3) and, thus, the mobility of ions in $\left[\mathrm{C}_{6} \mathrm{C}_{1} \mathrm{Im}\right][\mathrm{EHS}]$ is significantly higher as compared to those of $\left[\mathrm{P}_{4,4,4,4}\right][\mathrm{EHS}]$ and

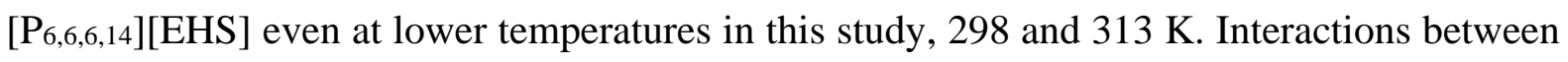
the constituent ions, which may lead to strong ion-pairing and a low ionicity in ILs, also control the ionic conductivity and the mobility of ions. Imidazolium-based ILs are known to have more mobile ions than tetraalkylammonium- and tetraalkylphosphonium-based ILs. ${ }^{47}$ The latter can be explained by the fact that the positive $(+1)$-charge of the imidazolium cation is delocalised on nitrogen and carbon atoms of the imidazolium heterocycle, which results in a weaker coulombic interaction between ions and a higher ionicity in imidazolium-based ILs. ${ }^{47,} 48$ Therefore, more free ions are available in $\left[\mathrm{C}_{6} \mathrm{C}_{1} \mathrm{Im}\right][\mathrm{EHS}]$ as compared to $\left[\mathrm{P}_{4,4,4,4}\right][\mathrm{EHS}]$ and $\left[\mathrm{P}_{6,6,6,14}\right][\mathrm{EHS}]$ that results in higher specific capacitance values for MWCNTs/[C6 $\left.\mathrm{C}_{1} \mathrm{Im}\right][\mathrm{EHS}]$ capacitors compared to those of the other two electrolytes in this study.

We further investigated the energy storage performance of the SAILs in this study. The ECW for aqueous electrolytes is only $1 \mathrm{~V}$ and that for other organic solvent-based electrolytes is around 1.5-3 V, while the ECW for the neat SAILs in this work is between 4 and $5 \mathrm{~V}$ in a temperature range from 298 to $373 \mathrm{~K}$. Due to a wider ECW, the energy density of a capacitor is significantly larger for MWCNTs-based supercapacitors with neat SAILs as electrolytes when compared to aqueous- and organic-solvent-based electrolytes. The order of the specific capacitance and energy densities calculated from CV curves obtained at a scan rate of $2 \mathrm{mV} \mathrm{s}$ ${ }^{1}$ is the following: $\left[\mathrm{C}_{6} \mathrm{C}_{1} \mathrm{Im}\right][\mathrm{EHS}]>\left[\mathrm{P}_{4,4,4,4}\right][\mathrm{EHS}]>\left[\mathrm{N}_{8,8,8,8}\right][\mathrm{EHS}]>\left[\mathrm{P}_{6,6,6,14}\right][\mathrm{EHS}]$ in the whole temperature range studied (see Figures 8(a) and 8(b)). (Figure S15 in the ESI shows 
CV curves obtained at $2 \mathrm{mV} \mathrm{s}^{-1}$ for MWCNTs/[C $\left.{ }_{6} \mathrm{C}_{1} \mathrm{Im}\right][\mathrm{EHS}]$ and MWCNTs/[P $\left.4,4,4,4\right][\mathrm{EHS}]$ capacitors at different temperatures.) The data for tests on a MWCNTs/[N $8,8,8,8][\mathrm{EHS}]$ capacitor was taken from our previous study. ${ }^{12}$ The energy density and the power density values at different scan rates for MWCNTs/SAILs supercapacitors are also shown in Figures S16 and S17 in the ESI. Note that $\left[\mathrm{P}_{4,4,4,4]}[\mathrm{EHS}]\right.$ can be used as an electrolyte even at rather low temperatures, 253 and $273 \mathrm{~K}$, but both the specific capacitance and the energy density are very low at these temperatures, because of a low ionic mobility in the SAIL at these temperatures (see Figures 8 (a) and 8(b)).
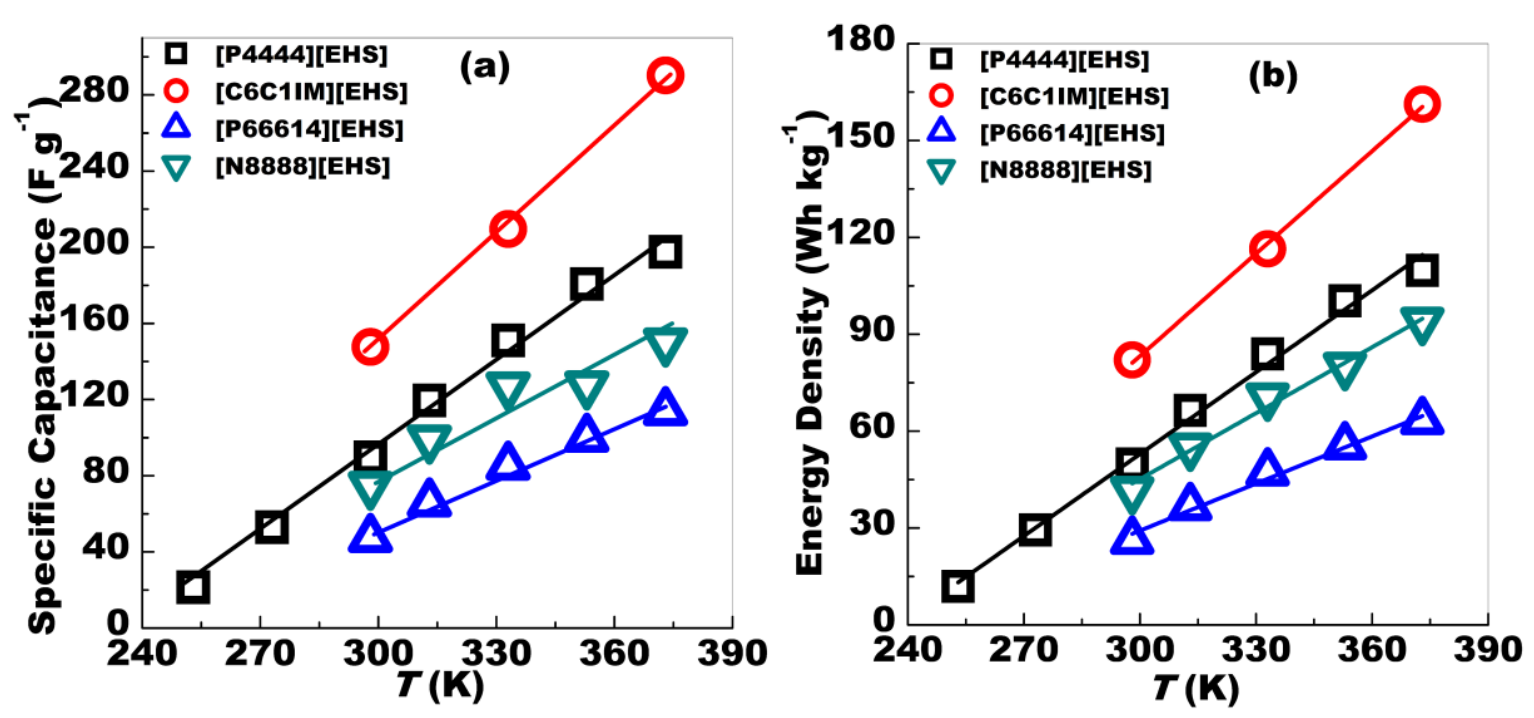

Figure 8. The specific capacitance (a), and the energy density (b) of MWCNTs/SAILs capacitors calculated from $\mathrm{CV}$ curves obtained at $2 \mathrm{mV} \mathrm{s}^{-1}$ and at different temperatures.

Supercapacitors with $\left[\mathrm{P}_{6,6,6,14}\right][\mathrm{EHS}],\left[\mathrm{N}_{8,8,8,8}\right][\mathrm{EHS}]$ and $\left[\mathrm{P}_{4,4,4,4}\right][\mathrm{EHS}]$ as electrolytes have rather low specific capacitance values, these SAILs can, in principle, be used in a wide temperature interval, from 253 to $373 \mathrm{~K}$. In contrary, a WMCNTs-based supercapacitor with $\left[\mathrm{C}_{6} \mathrm{C}_{1} \mathrm{Im}\right][\mathrm{EHS}]$ as an electrolyte has high specific capacitance values (from ca. 140 to $290 \mathrm{~F}$ $\mathrm{g}^{-1}$ at 298 to $373 \mathrm{~K}$, respectively) and these devices can be used at and above the room temperature, because this SAIL has its melting point at ca. $298 \mathrm{~K}$. However, at higher temperatures both $\left[\mathrm{P}_{4,4,4,4}\right][\mathrm{EHS}]$ and $\left[\mathrm{C}_{6} \mathrm{C}_{1} \mathrm{Im}\right][\mathrm{EHS}]$ outperform the other two electrolytes $\left(\left[\mathrm{P}_{6,6,6,14}\right][\mathrm{EHS}]\right.$ and $\left.\left[\mathrm{N}_{8,8,8,8}\right][\mathrm{EHS}]^{12}\right)$ in terms of both the specific capacitance and the energy density. Therefore, both $\left[\mathrm{C}_{6} \mathrm{C}_{1} \mathrm{Im}\right][\mathrm{EHS}]$ and $\left[\mathrm{P}_{4,4,4,4}\right][\mathrm{EHS}]$ can be considered as suitable electrolytes for electric storage applications in a wide temperature range, at least from 298 to $373 \mathrm{~K} .{ }^{49}$ Many conventional aqueous (for example, $6 \mathrm{M} \mathrm{KOH}(\mathrm{aq})$ ) and organic-solvent-based 
electrolyte solutions have low boiling points and a low thermal stability that limit their use at high temperatures. ${ }^{25,50,51}$ For comparison, the specific capacitance, the energy density and the power density values of a MWCNTs/[P $\left.\mathrm{P}_{4,4,4,4}\right][\mathrm{EHS}]$ are tabulated in Table 1 . The data in this table was calculated from CV curves (see Figure S18 in the ESI) obtained at scan rates of 2 and $5 \mathrm{mV} \mathrm{s}^{-1}$, ECW of $5 \mathrm{~V}$ and at two different temperatures, 298 and $373 \mathrm{~K}$, i.e. with four different sets of parameters. Note that different sets of the experimental parameters result in optimum values for the specific capacitance and the energy density (at $2 \mathrm{mV} \mathrm{s}^{-1}$ and $373 \mathrm{~K}$ ) and the power density (at $5 \mathrm{mV} \mathrm{s}^{-1}$ and $373 \mathrm{~K}$ ). Therefore, the performance of this type of supercapacitors can be further optimised depending on specific applications of this type of electric devices.

Table 1. The specific capacitance, the energy density and the power density of a MWCNTs/[P4,4,4,4][EHS] supercapacitor at 298 and $373 \mathrm{~K}$ with $\mathrm{ECW}=5 \mathrm{~V}$.

\begin{tabular}{|c|c|c|c|c|c|c|}
\hline $\begin{array}{c}\text { Temperature } \\
\text { (K)/ Scan } \\
\text { Rate }\end{array}$ & \multicolumn{3}{|c|}{$2 \mathrm{mV} \mathrm{s}^{-1}$} & \multicolumn{3}{c|}{$5 \mathrm{mV} \mathrm{s}^{-1}$} \\
\hline & $\begin{array}{c}C_{\text {elec }} \\
\left(\mathrm{F} \mathrm{g}^{-1}\right)\end{array}$ & $\begin{array}{c}\text { Energy Density } \\
\left(\mathrm{Wh} \mathrm{kg}^{-1}\right)\end{array}$ & $\begin{array}{c}\text { Power density } \\
\left(\mathrm{kW} \mathrm{kg}^{-1}\right)\end{array}$ & $\begin{array}{c}C_{\text {elec }} \\
\left(\mathrm{F} \mathrm{g}^{-1}\right)\end{array}$ & $\begin{array}{c}\text { Energy Density } \\
\left(\mathrm{Wh} \mathrm{kg}^{-1}\right)\end{array}$ & $\begin{array}{c}\text { Power density } \\
\left(\mathrm{kW} \mathrm{kg}^{-1}\right)\end{array}$ \\
\hline 298 & 132 & 74 & 106 & 87 & 48 & 174 \\
\hline 373 & 285 & 158 & 228 & 229 & 127 & 458 \\
\hline
\end{tabular}

Similarly, high values for the energy density and the power density were obtained at scan rates of 2 and $5 \mathrm{mV} \mathrm{s}^{-1}$ for a MWCNTs/[P $\left.6,6,6,14\right][\mathrm{EHS}]$ capacitor at different temperatures in the electrochemical potential window of $5 \mathrm{~V}$ (from -2.5 to $+2.5 \mathrm{~V}$ ) (see Figure S19 in the ESI). Therefore, both MWCNTs/[P4,4,4,4][EHS] and MWCNTs/[P6,6,6,14][EHS] can be used in high energy storage devices with ECW up to $5 \mathrm{~V}$, particularly, at elevated temperatures, to facilitate high values for the specific capacitance, the energy density and the power density.

To further compare the effect of size and structure of cations, $\left[\mathrm{C}_{6} \mathrm{C}_{1} \operatorname{Im}\right]^{+},\left[\mathrm{P}_{4,4,4,4}\right]^{+}$and $\left[\mathrm{P}_{6,6,6,14}\right]^{+}$on the performance of supercapacitors, we performed a range of additional electrochemical measurements on MWCNTs/SAILs devices.

\section{Electrochemical Impedance Spectroscopy (EIS):}

The EIS analysis provides a more fundamental understanding of electrode/electrolyte interface behaviour, ion diffusion and bulk properties of the electrolytes, etc., all important for a good 
performance of electric energy storage devices. ${ }^{52-54}$ The EIS data analysis provides the chargetransfer resistance $\left(R_{c t}\right)$ and the solution resistance $\left(R_{s}\right)$ as a function of AC frequency. Figure 9 shows the impedance spectra (Nyquist plots) of SAILs in this study at different temperatures. The Nyquist plots show a semicircle in the high frequency region, the Warburg line in the intermediate frequency region and almost a vertical line in the low frequency region, reflecting details of the charge storage mechanism of a system under study. ${ }^{55}$ Nyquist plots were fitted using a modified Randal's circuit (see Figure S20 in the ESI) with RelaxIS 3 software. The circuit in this analysis comprises $R_{s}$ (solution resistance), $R_{c t}$ (charge transfer resistance), CPE (constant phase element), $W$ (Warburg component), and $C_{d l}$ (double layer capacitance). The Warburg diffusion regions (with slopes $\sim 45^{\circ}$ from the horizontal axes) are clearly visible in Nyquist plots for SAILs in this study (see Figure 9). Steeper slopes signify higher diffusivity of ions entering the pores in electrodes, which is more prominent for $\left[\mathrm{C}_{6} \mathrm{C}_{1} \mathrm{Im}\right][\mathrm{EHS}]$ compared to $\left[\mathrm{P}_{4,4,4,4}\right][\mathrm{EHS}]$ and $\left[\mathrm{P}_{6,6,6,14]}\right]$ EHS $]$ (see insets in Figure 9). The steep rising trend of the imaginary part (-Z') with respect to the real part $\left(Z^{\prime}\right)$ of the impedance in the lower frequency range is observed in Nyquist plots for the SAILs particularly at high temperatures (333, 353 and $373 \mathrm{~K}$ ) that shows a better capacitive behaviour of the capacitor. The intersection between the vertical line and the real $Z$ ' axis corresponds to the equivalent series resistance (ESR) and was estimated by an extrapolation method via Origin Pro 8.0 software. Values are given in Table 3 (see also Figure S21 in the ESI). The ESR shifted to lower values upon increasing the temperature, which confirms the increasing ion conductance and mobility at higher temperatures. 

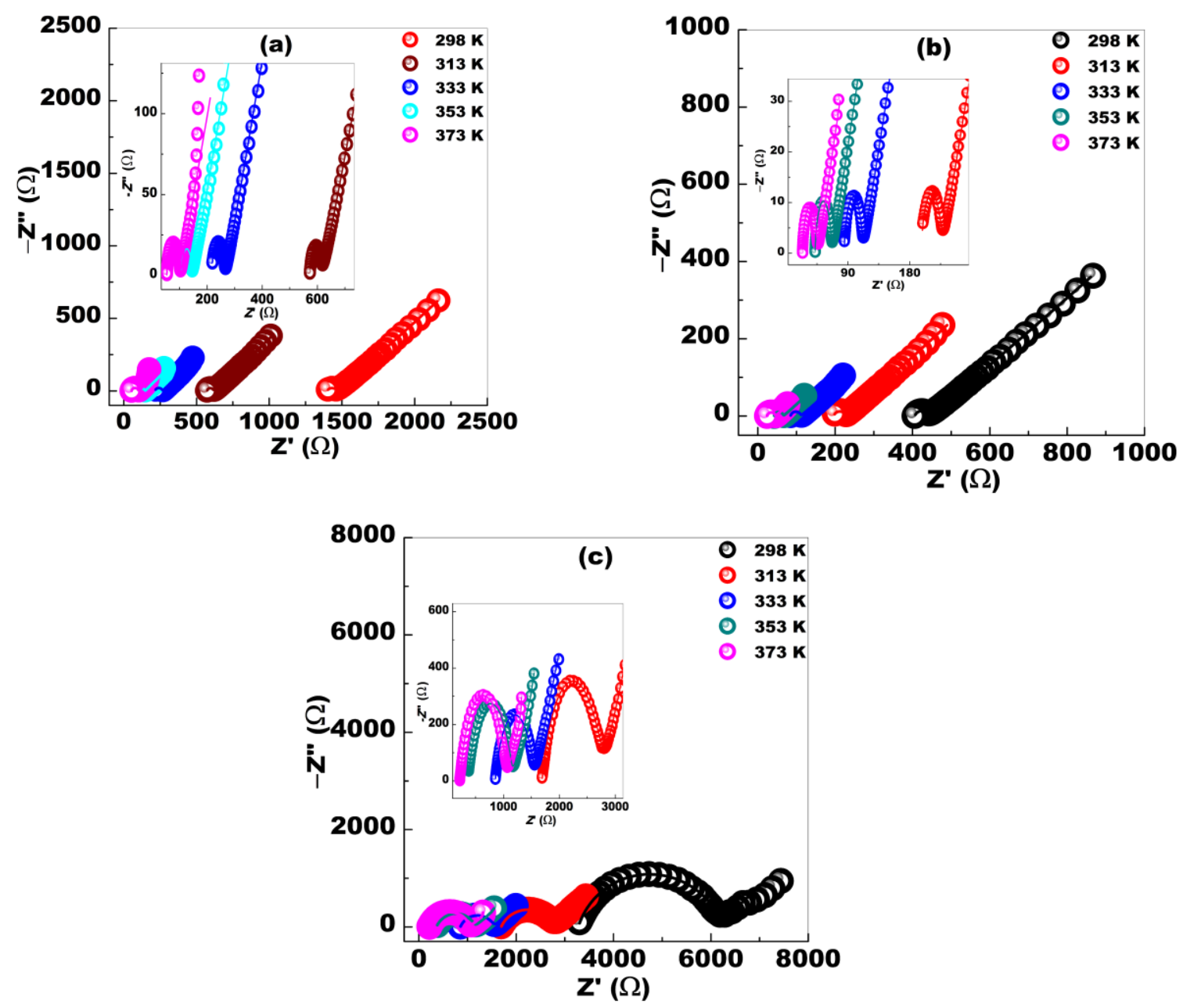

Figure 9. Nyquist plots at different temperatures for an MWCNT-based electrode with neat

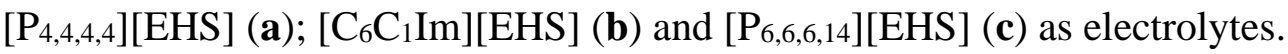

The Nyquist plots show small semicircles in the high-frequency region for all SAILs in the order of $\left.\left[\mathrm{C}_{6} \mathrm{C}_{1} \mathrm{Im}\right][\mathrm{EHS}]<\left[\mathrm{P}_{4,4,4,4]}\right] \mathrm{EHS}\right]<\left[\mathrm{P}_{6,6,6,14}\right][\mathrm{EHS}]$ that confirms a faster charge transfer and a higher capacitance for $\left[\mathrm{C}_{6} \mathrm{C}_{1} \mathrm{Im}\right][\mathrm{EHS}]$ in the whole temperature range. The $R_{s}$ and $R_{c t}$ values are given in Table 2 for a MWCNT-based electrode and different electrolytes. Also, for neat $\left[\mathrm{P}_{4,4,4,4}\right][\mathrm{EHS}]$, with an increase in temperature, the $R_{s}$ and $R_{c t}$ significantly decrease, from 1856 to $54 \Omega$ and from 14510 to $48 \Omega$, respectively, for temperatures from 253 to $373 \mathrm{~K}$. For $\left[\mathrm{P}_{6,6,6,14]}[\mathrm{EHS}]\right.$, corresponding values for both $R_{s}$ and $R_{c t}$ are much lower at the same temperatures. 
Table 2. The solution resistance $\left(R_{s}\right)$ and the charge transfer resistance $\left(R_{c t}\right)$ values obtained from the Nyquist plots.

\begin{tabular}{|c|c|c|c|c|c|c|}
\hline \multirow{2}{*}{$\begin{array}{c}\text { Temperature } \\
(\mathbf{K})\end{array}$} & \multicolumn{2}{|c|}{$\left[\mathbf{C}_{\mathbf{6}} \mathbf{C}_{\mathbf{1}} \mathbf{I m}\right][\mathbf{E H S}]$} & \multicolumn{2}{c|}{$\left[\mathbf{P}_{\mathbf{4 , 4}, \mathbf{4 , 4}][\mathbf{E H S}]}\right.$} & \multicolumn{2}{c|}{$\left[\mathbf{P}_{\mathbf{6}, \mathbf{6 , 6}, \mathbf{1 4}][\mathrm{EHS}]}\right.$} \\
\cline { 2 - 7 } & $R_{s}(\Omega)$ & $R_{c t}(\Omega)$ & $R_{s}(\Omega)$ & $R_{c t}(\Omega)$ & $R_{s}(\Omega)$ & $R_{c t}(\Omega)$ \\
\hline 253 & & & $1856 \pm 130$ & $14510 \pm 136$ & & \\
\hline 273 & & & $1607 \pm 90$ & $3631 \pm 15$ & & $2890 \pm 18$ \\
\hline 298 & $405 \pm 1$ & $32 \pm 0.90$ & $1398 \pm 1$ & $136 \pm 3$ & $3277 \pm 10$ & $1080 \pm 2$ \\
\hline 313 & $196 \pm 1$ & $28 \pm 0.68$ & $570 \pm 1$ & $37 \pm 1$ & $1691 \pm 1$ & $691 \pm 1$ \\
\hline 333 & $84 \pm 0.15$ & $26 \pm 0.40$ & $215 \pm 1$ & $52 \pm 1$ & $853 \pm 1$ & $878 \pm 2$ \\
\hline 353 & $42 \pm 0.08$ & $23 \pm 0.20$ & $105 \pm 1$ & $42 \pm 1$ & $686 \pm 1$ & $846 \pm 2$ \\
\hline 373 & $24 \pm 0.19$ & $21 \pm 0.32$ & $54 \pm 1$ & $48 \pm 1$ & $217 \pm 1$ & \\
\hline
\end{tabular}

Table 3. The equivalent series resistance (ESR) values obtained from the Nyquist plots by extrapolation.

\begin{tabular}{|c|c|c|c|}
\hline $\begin{array}{c}\text { Temperature } \\
(\mathbf{K})\end{array}$ & {$\left[\mathbf{C}_{\mathbf{6}} \mathbf{C}_{\mathbf{1}} \mathbf{I m}\right][\mathrm{EHS}]$} & {$\left[\mathbf{P}_{\mathbf{4}, \mathbf{4 , 4}, \mathbf{4}}\right][\mathbf{E H S}]$} & {$\left[\mathbf{P}_{\mathbf{6}, \mathbf{6}, \mathbf{6}, \mathbf{1 4}][\mathbf{E H S}]}\right.$} \\
\hline 333 & $221 \pm 2$ & $468 \pm 5$ & $1994 \pm 20$ \\
\hline 353 & $117 \pm 1$ & $264 \pm 3$ & $1517 \pm 15$ \\
\hline 373 & $72 \pm 1$ & $163 \pm 1$ & $1287 \pm 13$ \\
\hline
\end{tabular}

\section{Galvanostatic Charge Discharge (GCD)}

We further performed GCD experiments to check the performance of the capacitor. Figure 10 shows comparative GCD curves for the SAILs/MWCNT-based supercapacitor at different temperatures. We observed that all curves have similar isosceles triangular shapes that represent a typical pattern of a satisfactory capacitor behaviour for the studied supercapacitors. A steep profile for $I R_{d r o p}$ was observed for the SAILs at lower temperatures, 298 and $313 \mathrm{~K}$ at $0.14 \mathrm{~A} \mathrm{~g} \mathrm{~g}^{-1}$. Upon an increase in the current density, IRdrop further increased at these temperatures. This might be a result of a high viscosity of SAILs and a small pore size of the electrode material compared to the size of ions of the electrolyte. The IRdrop parameter corresponds to the ESR of the supercapacitor cell, which is associated with the diffusion mobility of the electrolyte ions travelling through the pores of the electrode. However, it can also be observed that the areas under the curve and the discharge period are different for each system in this study, being at a maximum at $373 \mathrm{~K}$ for the SAILs and exhibiting a better capacitive performance at $373 \mathrm{~K}$ compared to lower temperatures. The GCD curves at different current densities are provided in the ESI for $\left[\mathrm{P}_{4,4,4,4]}[\mathrm{EHS}]\right.$ at 0.07 and $0.11 \mathrm{~A} \mathrm{~g}^{-1}$ (see Figure 
S22 in the ESI) and for $\left[\mathrm{C}_{6} \mathrm{C}_{1} \mathrm{Im}\right][\mathrm{EHS}]$ at $0.11 \mathrm{~A} \mathrm{~g}^{-1}$ (see Figure S23 in the ESI). Whereas, for $\left[\mathrm{P}_{6,6,6,14}\right][\mathrm{EHS}] \mathrm{GCD}$ curves were obtained only at a very low current density of $0.014 \mathrm{~A} \mathrm{~g}^{-1}$ (see Figure S24 in the ESI) due to a high viscosity of this SAIL. The specific capacitance values were calculated from the GCD curves using the following equation: ${ }^{56}$

$$
C_{\text {elec }}=4 \frac{\mathrm{I} \Delta \mathrm{t}}{\mathrm{m} \Delta \mathrm{V}}
$$

where, $\Delta t$ is the discharge time, $\Delta V$ is the voltage difference, $I$ is current, and $m$ is a mass of the electrode.

Table 4 and 5 show values of $C_{\text {elec }}\left(\mathrm{F} \mathrm{g}^{-1}\right)$ and the energy density, $E\left(\mathrm{~W} \mathrm{~h} \mathrm{~kg}^{-1}\right)$ calculated from the GCD curves and $\mathrm{CV}$ curves at $10 \mathrm{mV} \mathrm{s}^{-1}$ for $\left[\mathrm{C}_{6} \mathrm{C}_{1} \mathrm{Im}\right][\mathrm{EHS}]$ and $\left[\mathrm{P}_{4,4,4,4]}[\mathrm{EHS}\right.$, respectively. The $C_{\text {elec }}$ values obtained from GCD curves at lower current densities are in a good agreement with those obtained from the CV curves.
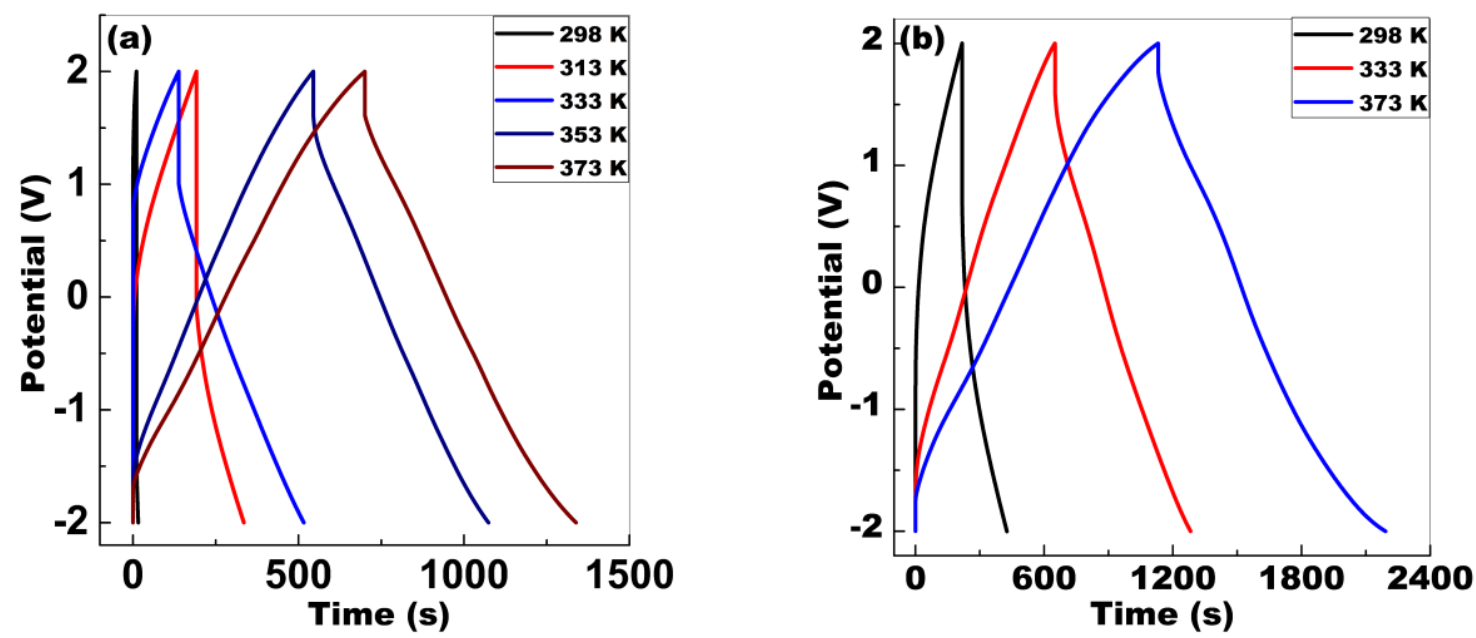

Figure 10. Galvanostatic charge discharge curves for an MWCNT-based electrode with neat $\left[\mathrm{P}_{4,4,4,4}\right][\mathrm{EHS}](\mathbf{a})$, and $\left[\mathrm{C}_{6} \mathrm{C}_{1} \mathrm{Im}\right][\mathrm{EHS}]$ (b) as electrolytes, at $0.14 \mathrm{~A} \mathrm{~g}^{-1}$ current density at different temperatures.

Table 4. Specific capacitance $\left(C_{\text {elec }}\right)$ and the energy density $(E)$ for a MWCNTs/[C $\left.{ }_{6} \mathrm{C}_{1} \mathrm{Im}\right][\mathrm{EHS}]$ capacitor.

\begin{tabular}{|c|c|c|c|c|c|c|}
\hline \multirow{2}{*}{$\begin{array}{c}\text { Temperature } \\
(\mathbf{K})\end{array}$} & \multicolumn{2}{|c|}{ CV at 10 $\mathbf{~ V s}^{-1}$} & \multicolumn{2}{c|}{ GCD at 0.11 $\mathbf{A ~ g}^{-1}$} & \multicolumn{2}{c|}{ GCD at 0.14 A g-1 } \\
\cline { 2 - 7 } & $C_{\text {elec }}\left(\mathrm{F} \mathrm{g} \mathrm{g}^{-1}\right)$ & $E\left(\mathrm{~W} \mathrm{~h} \mathrm{~kg}^{-1}\right)$ & $C_{\text {elec }}\left(\mathrm{F} \mathrm{g}^{-1}\right)$ & $E\left(\mathrm{~W} \mathrm{~h} \mathrm{~kg}^{-1}\right)$ & $C_{\text {elec }}\left(\mathrm{F} \mathrm{g}^{-1}\right)$ & $E\left(\mathrm{~W} \mathrm{~h} \mathrm{~kg}^{-1}\right)$ \\
\hline 298 & 71 & 40 & 66 & 33 & 44 & 22 \\
\hline 333 & 158 & 88 & 113 & 106 & 100 & 91 \\
\hline 373 & 224 & 125 & 180 & 180 & 160 & 159 \\
\hline
\end{tabular}


Table 5. Specific capacitance $\left(C_{\text {elec }}\right)$ and the energy density $(E)$ for a MWCNTs/[P $\left.4,4,4,4\right][\mathrm{EHS}]$ supercapacitor.

\begin{tabular}{|c|c|c|c|c|c|c|c|c|}
\hline \multirow{2}{*}{$\begin{array}{c}\text { Temperature } \\
\text { (K) }\end{array}$} & \multicolumn{2}{|c|}{$\mathrm{CV}$ at $10 \mathrm{mV} \mathrm{s}^{-1}$} & \multicolumn{2}{|c|}{ GCD at $0.07 \mathrm{~A} \mathrm{~g}^{-1}$} & \multicolumn{2}{|c|}{ GCD at $0.11 \mathrm{~A} \mathrm{~g}^{-1}$} & \multicolumn{2}{|c|}{ GCD at $0.14 \mathrm{~A} \mathrm{~g}^{-1}$} \\
\hline & $\begin{array}{l}C_{\text {elec }} \\
\left(\mathrm{F} \mathrm{g}^{-1}\right)\end{array}$ & $\begin{array}{c}E \\
\left(\mathrm{~W} \mathrm{~h} \mathrm{~kg}^{-1}\right)\end{array}$ & $\begin{array}{l}C_{\text {elec }} \\
\left(\mathrm{F} \mathrm{g}^{-1}\right)\end{array}$ & $\begin{array}{c}E \\
\left(\mathrm{~W} \mathrm{~h} \mathrm{~kg}^{-1}\right)\end{array}$ & $\begin{array}{l}C_{\text {elec }} \\
\left(\mathrm{F} \mathrm{g}^{-1}\right)\end{array}$ & $\begin{array}{c}E \\
\left(\mathrm{~W} \mathrm{~h} \mathrm{~kg}^{-1}\right)\end{array}$ & $\begin{array}{l}C_{\text {elec }} \\
\left(\mathrm{F} \mathrm{g}^{-1}\right)\end{array}$ & $\begin{array}{c}E \\
\left(\mathrm{~W} \mathrm{~h} \mathrm{~kg}^{-1}\right)\end{array}$ \\
\hline 298 & 34 & 19 & 25 & 9 & 10 & 1 & 5 & 1 \\
\hline 313 & 65 & 36 & 55 & 40 & 47 & 22 & 43 & 11 \\
\hline 333 & 106 & 59 & 77 & 71 & 74 & 55 & 72 & 45 \\
\hline 353 & 137 & 76 & 92 & 92 & 93 & 88 & 84 & 76 \\
\hline 373 & 158 & 88 & 117 & 118 & 112 & 112 & 101 & 92 \\
\hline
\end{tabular}

At the end of all aforementioned experiments, $500 \mathrm{CV}$ cycles with a scan rate of $50 \mathrm{mV} \mathrm{s}^{-1}$ at 298 and $333 \mathrm{~K}$ were recorded for an MWCNT-based electrode with $\left[\mathrm{C}_{6} \mathrm{C}_{1} \mathrm{Im}\right][\mathrm{EHS}]$ and

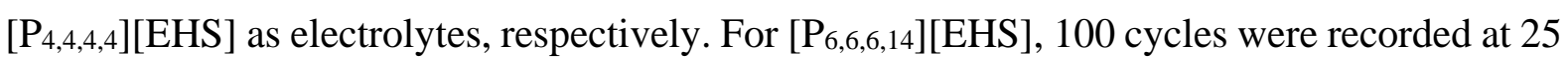
$\mathrm{mV} \mathrm{s}^{-1}$ at $298 \mathrm{~K}$ and 50 cycles were recorded at $25 \mathrm{mV} \mathrm{s}^{-1}$ at $373 \mathrm{~K}$. Figure 11 shows that $\left[\mathrm{P}_{4,4,4,4}\right][\mathrm{EHS}]$ exhibited a good capacitance retention $(98 \%)$, for $\left[\mathrm{C}_{6} \mathrm{C}_{1} \mathrm{Im}\right][\mathrm{EHS}]$ the capacitance increased with the number of cycles. For $\left[\mathrm{P}_{6,6,6,14}\right][\mathrm{EHS}], 99 \%$ retention was observed in capacitance after completing all the experiments. Figures S25 and S26 in the ESI show a well-overlapping CV-curves (the first and the last CV cycles). The EIS measurements were also performed before and after cyclic tests and showed a good overlap of the EIS data (see Figure S27 in the ESI). After completion of all the experiments from 298 to $373 \mathrm{~K}$ and the cyclic tests, the CV show good overlaps (see Figure S28 in the ESI) for the studied SAILs, which indicates a good thermal and electrochemical stability of all SAILs in this study. 

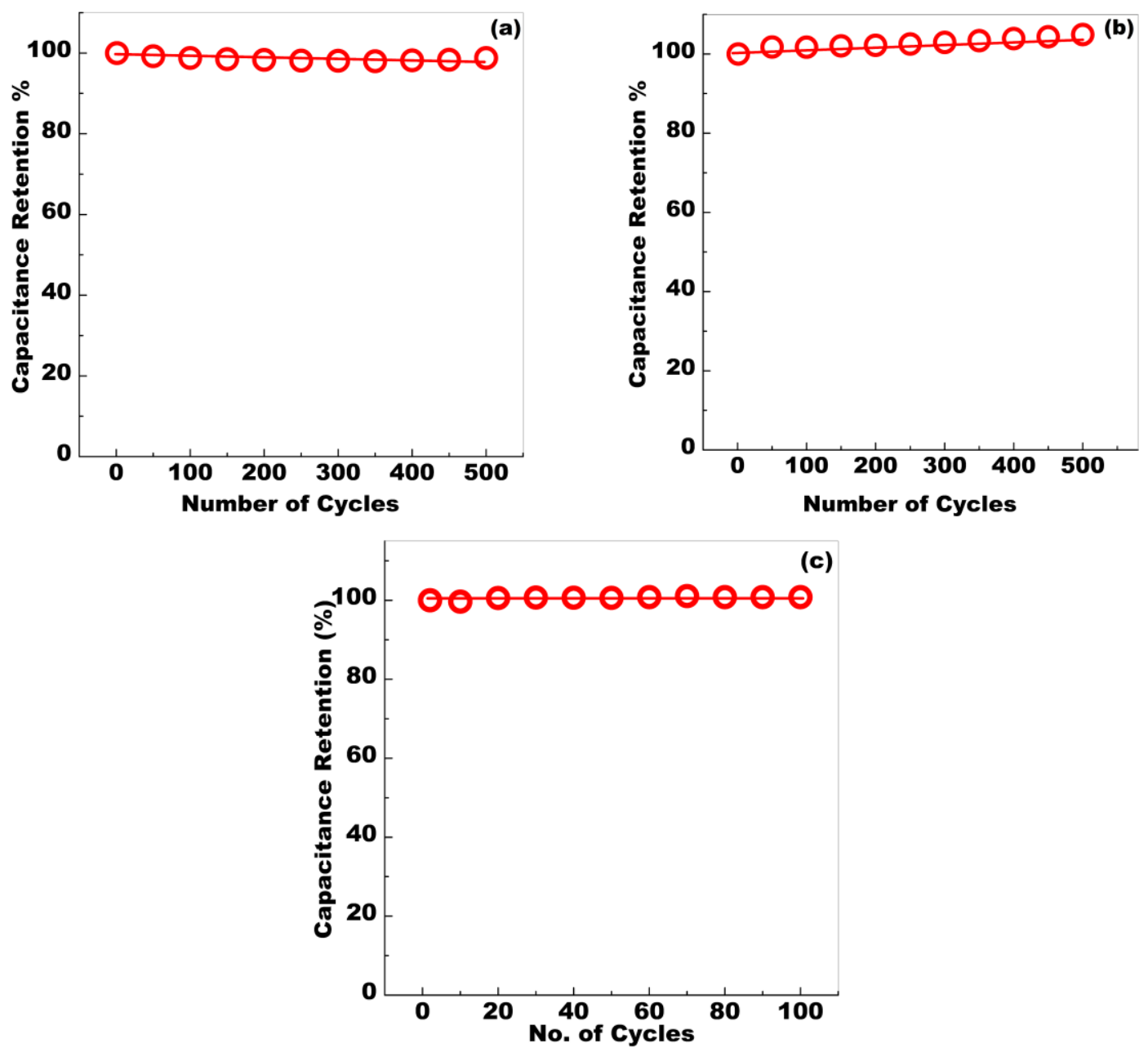

Figure 11. Capacitance retention of CV cycles at the scan rate of $50 \mathrm{mV} \mathrm{s}^{-1}$ and at $333 \mathrm{~K}$ after completing all the experiments up to $373 \mathrm{~K}$ for a MWCNTs/[P4,4,4,4][EHS] supercapacitor (a); at $50 \mathrm{mV} \mathrm{s}^{-1}$ and $298 \mathrm{~K}$ for a MWCNTs/[C $\left.6 \mathrm{C}_{1} \mathrm{Im}\right][\mathrm{EHS}]$ supercapacitor (b) and at $25 \mathrm{mV} \mathrm{s}^{-1}$ and $298 \mathrm{~K}$ for a MWCNTs/[P6,6,6,14][EHS] supercapacitor (c).

\section{Ragone plot}

We further quantified the power density and the energy density of the MWCNTs/SAILs supercapacitors in this study, as it is a crucial parameter in choosing an appropriate electrodeelectrolyte combination. The power density, $P$, and the energy density, $E$, calculated using Eqs. (2) and (3) were plotted against each other and generally referred as the Ragone plot. Figure 12 shows that MWCNTs $/\left[\mathrm{C}_{6} \mathrm{C}_{1} \mathrm{Im}\right][\mathrm{EHS}]$ outperforms other supercapacitors in this study in the temperature range from 298 to $373 \mathrm{~K}$. A comparison between the Ragone plots for all SAILs in this study at different temperatures infers that $\left[\mathrm{C}_{6} \mathrm{C}_{1} \mathrm{Im}\right][\mathrm{EHS}]$ has higher values for both the energy density and the power densities as compared to the other two SAIL electrolytes. 
For a MWCNTs/[C $\left.{ }_{6} \mathrm{C}_{1} \mathrm{Im}\right][\mathrm{EHS}]$ supercapacitor at the scan rate of $2 \mathrm{mV} \mathrm{s}^{-1}$ and at $298 \mathrm{~K}$, the energy density and the power density values were $82 \mathrm{~W} \mathrm{~h} \mathrm{~kg}^{-1}$ and $148 \mathrm{~kW} \mathrm{~kg}^{-1}$, respectively. These values can further be improved upon increasing the temperature to $373 \mathrm{~K}$, but keeping the scan rate the same $\left(2 \mathrm{mV} \mathrm{s}^{-1}\right)$ : both the energy density $\left(161 \mathrm{~W} \mathrm{~h} \mathrm{~kg}^{-1}\right)$ and the power density $\left(290 \mathrm{~kW} \mathrm{~kg}^{-1}\right)$ were almost doubled. Upon an increase of temperature from 298 to $373 \mathrm{~K}$, both the energy density and the power density have also increased for MWCNTs/[P4,4,4,4][EHS] and MWCNTs/[P6,6,6,14][EHS] supercapacitors: from 50 to $110 \mathrm{~W} \mathrm{~h} \mathrm{~kg}^{-1}$ and 90 to $198 \mathrm{~kW} \mathrm{~kg}^{-1}$; and 26 to $63 \mathrm{~W} \mathrm{~h} \mathrm{~kg}^{-1}$ and 47 to $114 \mathrm{~kW} \mathrm{~kg}^{-1}$, respectively. The electrochemical performance of studied supercapacitors is significantly better than that reported for MWCNTs/halogenated ILs as electrolytes. ${ }^{57-60}$
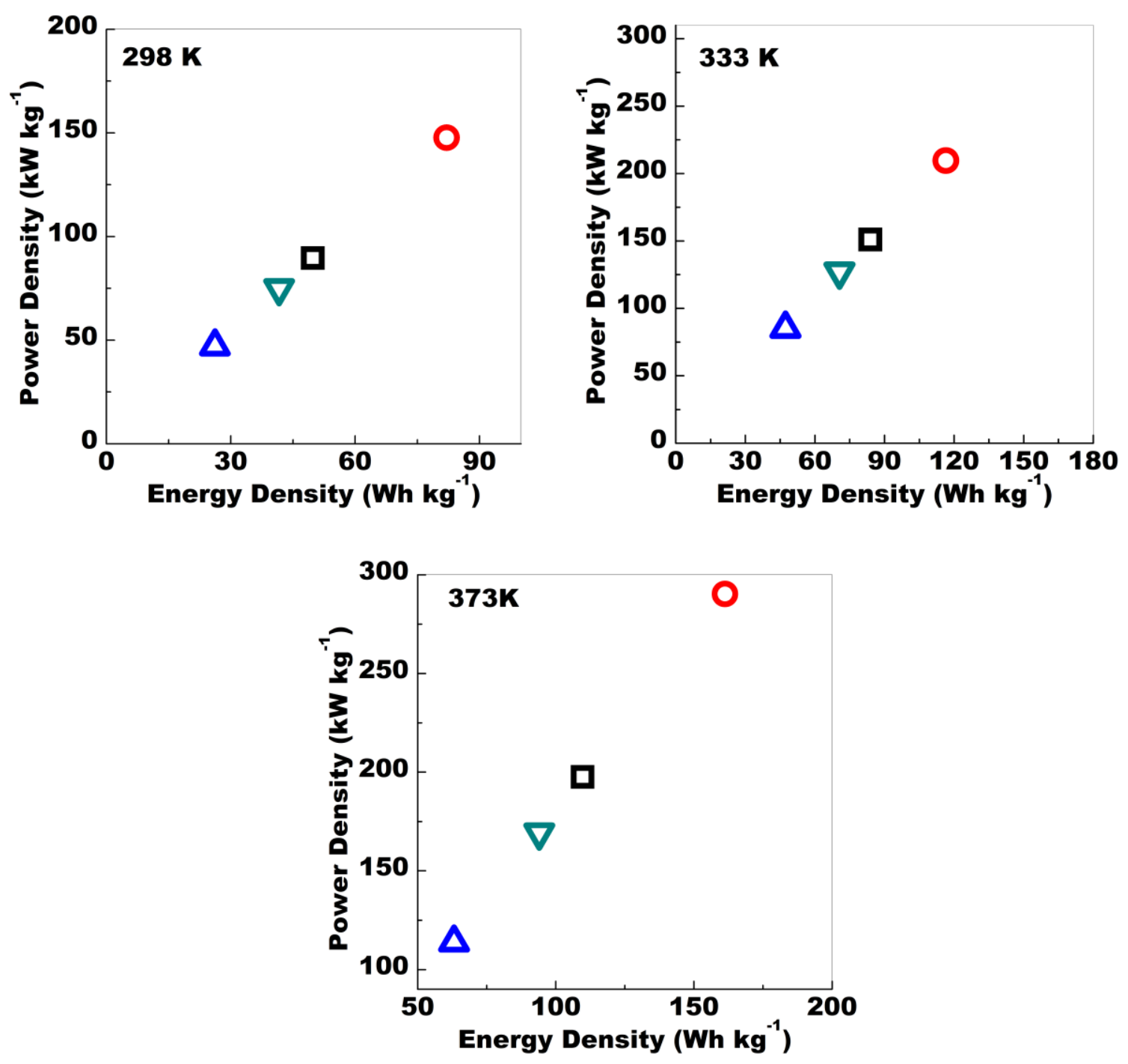
Figure 12. Ragone plots for MWCNT/SAILs capacitors with SAILs as following: $\left[\mathrm{C}_{6} \mathrm{C}_{1} \mathrm{Im}\right][\mathrm{EHS}](\mathrm{O}),\left[\mathrm{P}_{4,4,4,4}\right][\mathrm{EHS}](\square),\left[\mathrm{P}_{6,6,6,14}\right][\mathrm{EHS}](\triangle)$, and $\left[\mathrm{N}_{8,8,8,8}\right][\mathrm{EHS}](\nabla)^{12}$. Data obtained at the scan rate of $2 \mathrm{mV} \mathrm{s}^{-1}$ at different temperatures, 298, 333 and $373 \mathrm{~K}$.

After a thorough comparative analysis, we conclude that SAILs, such as $\left[\mathrm{C}_{6} \mathrm{C}_{1} \mathrm{Im}\right][\mathrm{EHS}]$, $\left[\mathrm{P}_{4,4,4,4}\right][\mathrm{EHS}],\left[\mathrm{P}_{6,6,6,14}\right][\mathrm{EHS}]$ from this study and $\left[\mathrm{N}_{8,8,8,8}\right][\mathrm{EHS}]$ (from our previous study) ${ }^{12}$ can be considered a value-added electrolytes in MWCNTs-based supercapacitor devices with a high specific capacitance, energy density and power density over a wide operating temperature range and with a good thermal, chemical and electrochemical stability. Comparing supercapacitors with different electrode materials and electrolytes, mainly ionic liquids, reported previously, we infer that the MWCNTs-based supercapacitors in combination with SAILs from the current study perform satisfactorily well in a wide range of temperatures. Data for aqueous, organic and IL-based electrolytes are also given for comparison in the Ragone plot in Figure 13. The latter plot shows that studied here SAILs outperform other up-to-now reported electrolytes in terms of combined the power density and the energy density performance.

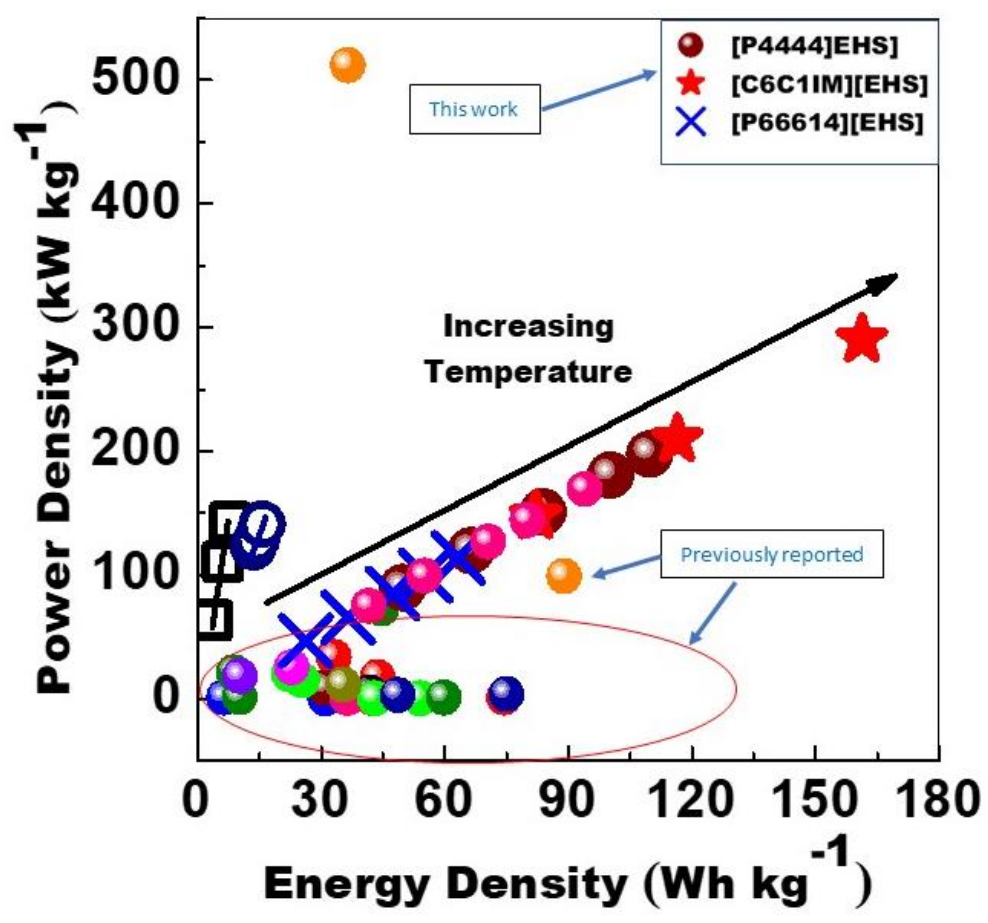

Figure 13. Ragone plots for a supercapacitor cell with MWCNT-based electrodes and neat

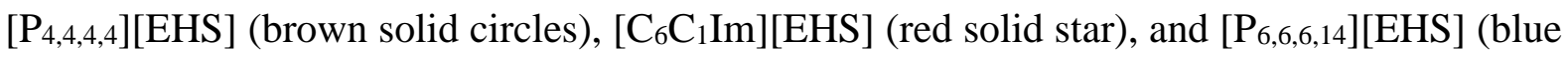
cross). ( $P$ and $E$ were calculated from $\mathrm{CV}$ curves obtained at a scan rate of $2 \mathrm{mV} \mathrm{s}^{-1}$ ). $6 \mathrm{M}$ 
$\mathrm{KOH}(\mathrm{aq})$ (black squares), neat $\left[\mathrm{N}_{8,8,8,8}\right][\mathrm{EHS}]$ (pink solid circles), 50:50 wt\% binary mixture of $\left[\mathrm{N}_{8,8,8,8}\right][\mathrm{EHS}]$ with $\mathrm{AcN}$ as electrolytes (dark-blue open circles) from ref. ${ }^{12}$ All other solid data points have been taken from the literature for a comparison; blue ${ }^{57}$, wine ${ }^{58}$, royal blue ${ }^{60}$, red $^{61}$, black $^{62}$, pink $^{63}$, green ${ }^{64}$, olive ${ }^{65}$, orange ${ }^{66}$, violet $^{67}$, dark yellow ${ }^{68}$ and magenta ${ }^{69}$.

\section{Conclusions}

Novel room-temperature surface active ionic liquids (SAILs) composed of different cations $\left.\left(\left[\mathrm{P}_{4,4,4,4}\right]^{+},\left[\mathrm{C}_{6} \mathrm{C}_{1} \mathrm{Im}\right]^{+},\left(\left[\mathrm{P}_{6,6,6,14}\right]^{+}\right) \text {and the 2-ethylhexyl sulfate anion ([EHS }\right]^{-}\right)$were synthesised and thoroughly characterised as electrolytes in MWCNTs-based supercapacitors. Interestingly, these non-halogenated SAILs with the [EHS $^{-}$as anion are liquids in a wide temperature range, whereas other halogenated ILs containing tetrabutylphosphonium or tetraalkylammonium as cations and halogen-containing anions, are solid in nature. The specific capacitance values $\left(C_{\text {elec }}\right)$ for MWCNTs/SAILs systems in this study are comparable or even higher to those previously reported for other types of SAILs. This study further validates a recently suggested concept that SAILs can be used as improved and safer electrolytes in supercapacitor cells in a wide range of temperatures and at extended electrochemical potential windows (ECW) to 4-5 $\mathrm{V}$ that is much wider than ECWs of aqueous and organic solvent-based electrolytes. The studied SAILs are economical and environmentally benign. Therefore, they can be used at a large scale without polluting the environment. The degradation temperature of SAILs in this study is above $550 \mathrm{~K}$. Therefore, MWCNTs/SAILs systems could potentially be further studied even above $373 \mathrm{~K}$, which is the temperature limit of Autolab potentiostat used in this study. At $298 \mathrm{~K}$ and at the scan rate of $2 \mathrm{mV} \mathrm{s}^{-1}$ and ECW $=4 \mathrm{~V}$, the specific capacitance was measured to be 148, 90 and $47 \mathrm{~F} \mathrm{~g}^{-1}$ for supercapacitors with MWCNT-based electrodes and $\left[\mathrm{C}_{6} \mathrm{C}_{1} \mathrm{Im}\right][\mathrm{EHS}],\left[\mathrm{P}_{4,4,4,4}\right][\mathrm{EHS}]$ and $\left[\mathrm{P}_{6,6,6,14}\right][\mathrm{EHS}]$ as electrolytes, while the energy density values were 82,50 , and $26 \mathrm{~W} \mathrm{~h} \mathrm{~kg}^{-1}$, respectively. From a three- to four-fold increase in the specific capacitance and the energy density values was measured for the afore above systems at the same experimental conditions, but upon an increase of temperature to $373 \mathrm{~K}: 290,198$ and $114 \mathrm{~F} \mathrm{~g}^{-1}$ and 161, 110 and $63 \mathrm{~W} \mathrm{~h} \mathrm{~kg}^{-1}$, respectively. Therefore, these novel SAILs can be considered as suitable electrolytes for high-temperature applications, such as powering energy devices in the oil and gas industries and in military and space applications. Overall, MWCNTs/[C $\left.6 \mathrm{C}_{1} \mathrm{Im}\right][\mathrm{EHS}]$ and MWCNTs/[P4,4,4,4][EHS] supercapacitors outperformed other systems with SAILs electrolytes in this and previous studies at variable temperatures and in a 
wide electrochemical potential range (4-5 V) along with a good thermal, electrochemical and cyclic stability of these SAILs. Therefore, both $\left[\mathrm{C}_{6} \mathrm{C}_{1} \mathrm{Im}\right][\mathrm{EHS}]$ and $\left[\mathrm{P}_{4,4,4,4}\right][\mathrm{EHS}]$ can be considered as "electrolytes-of-the-choice" in various high-temperature applications. This paves the way for building "designer" SAILs, since there is a large number of possible anion-cation combinations, which can be exploited to develop non-halogenated and environmentally benign ILs for next-generation electric energy storage devices.

\section{Conflicts of Interest}

There are no conflicts of interest to declare.

\section{Acknowledgements}

The Kempe Foundation in memory of J. C. and Seth M. Kempe is gratefully acknowledged for the financial support in the form of a stipend for P.J. (Grant No. JCK-1810), and for projects SMK-1945, JCK-1306 and JCK-1433 and the laboratory fund at LTU for providing grants, from which electrochemical equipment and a $400 \mathrm{MHz}$ Bruker Aeon/Avance III NMR spectrometer at LTU have been purchased.

\section{References:}

1. Z. Lei, B. Chen, Y. M. Koo and D. R. MacFarlane, Chem. Rev., 2017, 117, 6633-6635.

2. M. Galiński, A. Lewandowski and I. Stępniak, Electrochim. Acta, 2006, 51, 5567-5580.

3. M. J. Earle and K. R. Seddon, Clean Solvents, 2002, 819, 10-25.

4. M. Armand, F. Endres, D. R. MacFarlane, H. Ohno and B. Scrosati, Nat. Mater., 2009, 8, 621-629.

5. D. R. MacFarlane, M. Forsyth, P. C. Howlett, M. Kar, S. Passerini, J. M. Pringle, H. Ohno, M. Watanabe, F. Yan, W. J. Zheng, S. G. Zhang and J. Zhang, Nat. Rev. Mater., 2016, 1, 15005, 1-15.

6. A. Brandt, S. Pohlmann, A. Varzi, A. Balducci and S. Passerini, MRS Bull., 2013, 38, 554-559.

7. J. Z. Sun, D. R. MacFarlane and M. Forsyth, Ionics, 1997, 3, 356-362.

8. J. Sun, M. Forsyth and D. R. MacFarlane, J. Phys. Chem. B, 1998, 102, 8858-8864.

9. K. Tsunashima and M. Sugiya, Electrochem. Commun., 2007, 9, 2353-2358.

10. K. Shimizu, A. A. Padua and J. N. Canongia Lopes, J. Phys. Chem. B, 2010, 114, 15635-15641. 
11. P. J. Griffin, A. P. Holt, Y. Wang, V. N. Novikov, J. R. Sangoro, F. Kremer and A. P. Sokolov, J. Phys. Chem. B, 2014, 118, 783-790.

12. P. Jain and O. N. Antzutkin, ACS Appl. Energy Mater., 2021, DOI: 10.1021/acsaem.1c01157.

13. M. Hilder, G. M. A. Girard, K. Whitbread, S. Zavorine, M. Moser, D. Nucciarone, M. Forsyth, D. R. MacFarlane and P. C. Howlett, Electrochim. Acta, 2016, 202, 100-109.

14. R. K. Blundell and P. Licence, Phys. Chem. Chem. Phys., 2014, 16, 15278-15288.

15. K. Yoshii, K. Yamaji, T. Tsuda, K. Tsunashima, H. Yoshida, M. Ozaki and S. Kuwabata, J. Phys. Chem. B, 2013, 117, 15051-15059.

16. X. Mao, P. Brown, C. Cervinka, G. Hazell, H. Li, Y. Ren, D. Chen, R. Atkin, J. Eastoe, I. Grillo, A. A. H. Padua, M. F. Costa Gomes and T. A. Hatton, Nat. Mater., 2019, 18, 1350-1357.

17. S. Pan, M. Yao, J. Zhang, B. Li, C. Xing, X. Song, P. Su and H. Zhang, Front Chem, 2020, 8, 261, 1-18.

18. T. M. Bandhauer, S. Garimella and T. F. Fuller, J. Electrochem. Soc., 2011, 158, R1$\mathrm{R} 25$.

19. M. V. Fedorov and A. A. Kornyshev, Chem. Rev., 2014, 114, 2978-3036.

20. M. Salanne, B. Rotenberg, K. Naoi, K. Kaneko, P. L. Taberna, C. P. Grey, B. Dunn and P. Simon, Nat. Energy, 2016, 1, 16070, 1-10.

21. M. Z. Bazant, B. D. Storey and A. A. Kornyshev, Phys. Rev. Lett., 2012, 109, 046102, $1-4$.

22. M. A. Gebbie, H. A. Dobbs, M. Valtiner and J. N. Israelachvili, Proc. Natl. Acad. Sci. USA, 2015, 112, 7432-7437.

23. H. Zhou, M. Rouha, G. Feng, S. S. Lee, H. Docherty, P. Fenter, P. T. Cummings, P. F. Fulvio, S. Dai, J. McDonough, V. Presser and Y. Gogotsi, ACS Nano, 2012, 6, 98189827.

24. M. A. Gebbie, M. Valtiner, X. Banquy, E. T. Fox, W. A. Henderson and J. N. Israelachvili, Proc. Natl. Acad. Sci. USA, 2013, 110, 9674-9679.

25. C. Zhong, Y. Deng, W. Hu, J. Qiao, L. Zhang and J. Zhang, Chem. Soc. Rev., 2015, 44, 7484-7539.

26. S. McDonald, T. Murphy, S. Imberti, G. G. Warr and R. Atkin, J. Phys. Chem. Lett., 2018, 9, 3922-3927.

27. P. Brown, C. P. Butts, J. Eastoe, D. Fermin, I. Grillo, H. C. Lee, D. Parker, D. Plana and R. M. Richardson, Langmuir, 2012, 28, 2502-2509. 
28. T. Y. Wu, S. G. Su, S. T. Gung, M. W. Lin, Y. C. Lin, C. A. Lai and I. W. Sun, Electrochim. Acta, 2010, 55, 4475-4482.

29. J. D. Holbrey, W. M. Reichert, R. P. Swatloski, G. A. Broker, W. R. Pitner, K. R. Seddon and R. D. Rogers, Green Chem., 2002, 4, 407-413.

30. R. P. Swatloski, J. D. Holbrey and R. D. Rogers, Green Chem., 2003, 5, 361-363.

31. S. C. Canobre, D. A. L. Almeida, C. P. Fonseca and S. Neves, Electrochim. Acta, 2009, 54, 6383-6388.

32. V. Khomenko, E. Raymundo-Piñero and F. Béguin, J. Power Sources, 2006, 153, $183-$ 190.

33. M. S. Wu and K. H. Lin, J. Phys. Chem. C, 2010, 114, 6190-6196.

34. A. T. Chidembo, K. I. Ozoemena, B. O. Agboola, V. Gupta, G. G. Wildgoose and R. G. Compton, Energy Environ. Sci., 2010, 3, 228-236.

35. P. Jain, V. R. Chaudhari and A. Kumar, Phys. Chem. Chem. Phys., 2019, 21, 2412624131.

36. A. I. Bhatt, I. May, V. A. Volkovich, M. E. Hetherington, B. Lewin, R. C. Thied and N. Ertok, J. Chem. Soc., Dalton Trans., 2002, 24, 4532-4534.

37. Y. Y. Cao and T. C. Mu, Ind. Eng. Chem. Res., 2014, 53, 8651-8664.

38. P. Simon and Y. Gogotsi, Acc. Chem. Res., 2013, 46, 1094-1103.

39. D. Pech, M. Brunet, H. Durou, P. Huang, V. Mochalin, Y. Gogotsi, P. L. Taberna and P. Simon, Nat. Nanotechnol., 2010, 5, 651-654.

40. K. Xie, X. Qin, X. Wang, Y. Wang, H. Tao, Q. Wu, L. Yang and Z. Hu, Adv. Mater., 2012, 24, 347-352.

41. X. W. Mao, X. Q. Yang, J. Wu, W. D. Tian, G. C. Rutledge and T. A. Hatton, Chem. Mater., 2015, 27, 4574-4585.

42. X. Mao, F. Simeon, G. C. Rutledge and T. A. Hatton, Adv. Mater., 2013, 25, 13091314.

43. S. H. Aboutalebi, A. T. Chidembo, M. Salari, K. Konstantinov, D. Wexler, H. K. Liu and S. X. Dou, Energy Environ. Sci., 2011, 4, 1855-1865.

44. E. Frackowiak, K. Jurewicz, S. Delpeux and F. Beguin, J. Power Sources, 2001, 97-8, 822-825.

45. E. Frackowiak, K. Jurewicz, K. Szostak, S. Delpeux and F. Beguin, Fuel Process. Technol., 2002, 77, 213-219.

46. E. Frackowiak, S. Delpeux, K. Jurewicz, K. Szostak, D. Cazorla-Amoros and F. Beguin, Chem. Phys. Lett., 2002, 361, 35-41. 
47. W. L. Yuan, X. Yang, L. He, Y. Xue, S. Qin and G. H. Tao, Front. Chem., 2018, 6, 59, $1-12$.

48. T. Welton, Biophys. Rev., 2018, 10, 691-706.

49. X. Lin, M. Salari, L. M. Arava, P. M. Ajayan and M. W. Grinstaff, Chem. Soc. Rev., 2016, 45, 5848-5887.

50. R. S. Borges, A. L. Reddy, M. T. Rodrigues, H. Gullapalli, K. Balakrishnan, G. G. Silva and P. M. Ajayan, Sci. Rep., 2013, 3, 2572, 1-6.

51. P. Simon and Y. Gogotsi, Nat. Mater., 2008, 7, 845-854.

52. B. A. Mei, O. Munteshari, J. Lau, B. Dunn and L. Pilon, J. Phys. Chem. C, 2018, 122, 194-206.

53. P. L. Taberna, P. Simon and J. F. Fauvarque, J. Electrochem. Soc., 2003, 150, A292A300.

54. B. E. Conway, in Electrochemical Supercapacitors: Scientific Fundamentals and Technological Applications, ed. B. E. Conway, Springer US, Boston, MA, 1999, DOI: 10.1007/978-1-4757-3058-6_1, pp. 1-9.

55. Y. Xu, Z. Lin, X. Zhong, X. Huang, N. O. Weiss, Y. Huang and X. Duan, Nat. Commun., 2014, 5, 4554, 1-8.

56. M. D. Stoller and R. S. Ruoff, Energy Environ. Sci., 2010, 3, 1294-1301.

57. H. T. Liu and G. Y. Zhu, J. Power Sources, 2007, 171, 1054-1061.

58. A. Balducci, R. Dugas, P. L. Taberna, P. Simon, D. Plée, M. Mastragostino and S. Passerini, J. Power Sources, 2007, 165, 922-927.

59. R. S. Borges, H. Ribeiro, R. L. Lavall and G. G. Silva, J. Solid State Electrochem., 2012, 16, 3573-3580.

60. R. Shao, J. Niu, J. Liang, M. Liu, Z. Zhang, M. Dou, Y. Huang and F. Wang, ACS Appl. Mater. Interfaces, 2017, 9, 42797-42805.

61. D. Q. Liu, Z. Jia and D. L. Wang, Carbon, 2016, 100, 664-677.

62. X. J. Li, J. Zhou, W. Xing, F. Subhan, Y. Zhang, P. Bai, B. J. Xu, S. P. Zhuo, Q. Z. Xue and Z. F. Yan, Electrochim. Acta, 2016, 190, 923-931.

63. X. Wang, C. X. Lu, H. F. Peng, X. Zhang, Z. K. Wang and G. K. Wang, J. Power Sources, 2016, 324, 188-198.

64. C. Chen, D. F. Yu, G. Y. Zhao, B. S. Du, W. Tang, L. Sun, Y. Sun, F. Besenbacher and M. Yu, Nano Energy, 2016, 27, 377-389.

65. L. Zhang, T. You, T. Zhou, X. Zhou and F. Xu, ACS Appl. Mater. Interfaces, 2016, 8, 13918-13925. 
66. J. Xu, Z. Tan, W. Zeng, G. Chen, S. Wu, Y. Zhao, K. Ni, Z. Tao, M. Ikram, H. Ji and Y. Zhu, Adv. Mater., 2016, 28, 5222-5228.

67. X. M. Fan, C. Yu, J. Yang, Z. Ling, C. Hu, M. D. Zhang and J. S. Qiu, Adv. Energy Mater., 2015, 5, 1401761-7.

68. Y. S. Yun, M. H. Park, S. J. Hong, M. E. Lee, Y. W. Park and H. J. Jin, ACS Appl. Mater. Interfaces, 2015, 7, 3684-3690.

69. N. N. Guo, M. Li, X. K. Sun, F. Wang and R. Yang, Green Chem., 2017, 19, 25952602.

Table of Content:

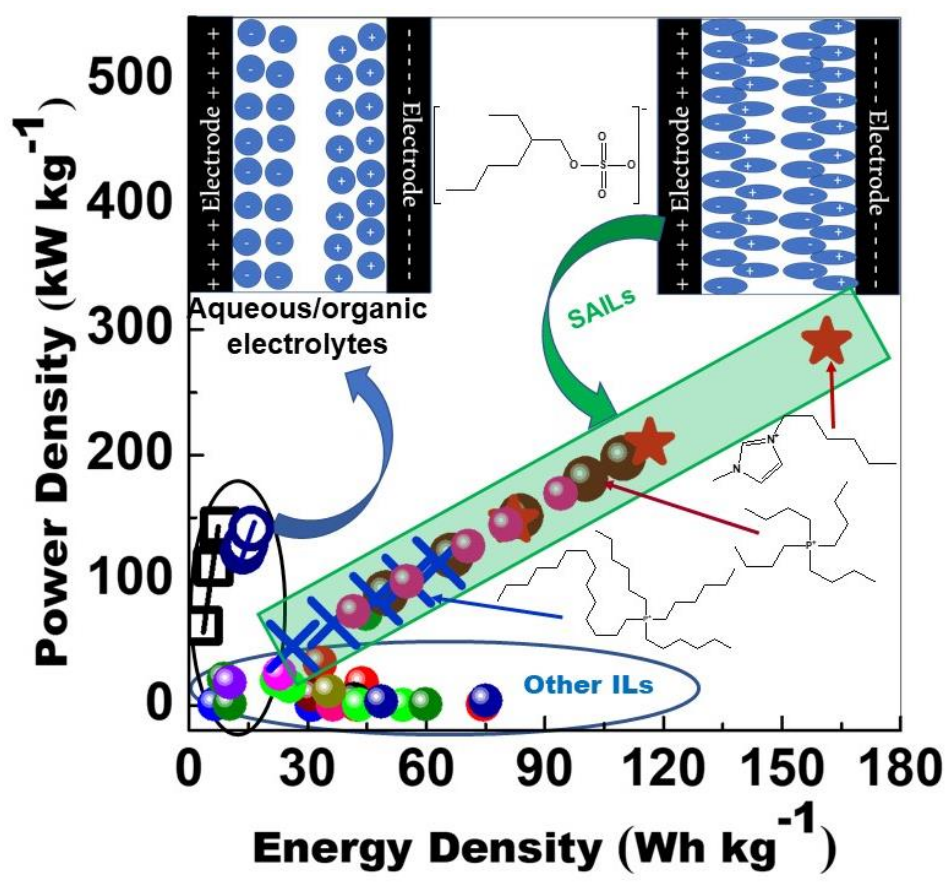

